Florida International University FIU Digital Commons

7-19-2012

\title{
Caretaker-Child Interactions At Bedtime: A Bidirectional Analysis of Noncompliant Bedtime Behavior
}

Desiree J. Espinal

Florida International University, despi007@fiu.edu

DOI: $10.25148 /$ etd.FI12080615

Follow this and additional works at: https://digitalcommons.fiu.edu/etd

\section{Recommended Citation}

Espinal, Desiree J., "Caretaker-Child Interactions At Bedtime: A Bidirectional Analysis of Noncompliant Bedtime Behavior" (2012). FIU Electronic Theses and Dissertations. 691.

https://digitalcommons.fiu.edu/etd/691 


\title{
FLORIDA INTERNATIONAL UNIVERSITY
}

Miami, Florida

\section{CARETAKER-CHILD INTERACTIONS AT BEDTIME: A BIDIRECTIONAL ANALYSIS OF NONCOMPLIANT BEDTIME BEHAVIOR}

\author{
A thesis submitted in partial fulfillment of \\ the requirements for the degree of \\ MASTER OF SCIENCE \\ in \\ PSYCHOLOGY
}

by

Desiree J. Espinal 
To: Dean Kenneth G. Furton

College of Arts and Sciences

This thesis, written by Desiree J. Espinal, and entitled Caretaker-Child Interactions at Bedtime: A Bidirectional Analysis of Noncompliant Bedtime Behavior, having been approved in respect to style and intellectual content, is referred to you for judgment.

We have read this thesis and recommend that it be approved.

Mary Levitt

Martha Pelaez

Jacob Gewirtz, Major Professor

Date of Defense: July 19, 2012

The thesis of Desiree J. Espinal is approved.

Dean Kenneth G. Furton

College of Arts and Sciences

Dean Lakshmi N. Reddi

University Graduate School

Florida International University, 2012 


\section{ACKNOWLEDGMENTS}

First and foremost, I would like to thank my committee members for all of their advice and guidance, especially Dr. Jacob Gewirtz, committee chairman. I would also like to thank Dr. Maricel Cigales, who did not serve on my committee but provided me with invaluable suggestions and feedback.

I deeply appreciate the help I received from all of my research assistants, who helped me transcribe and code what seemed like endless hours of data. Moreover, I offer my sincerest gratitude to my colleague, Paloma Rodriguez, for being there to answer my questions and for always being a major source of support.

A very special thanks to the Florida Education Fund for providing me with funding and, most importantly, an endless amount of support and encouragement.

Lastly, I would like to thank my family, especially my husband and my mother, for believing in me when I found it hard to believe in myself. Without their continued faith in me, I would not have been able to complete the project. 


\begin{abstract}
OF THE THESIS
CARETAKER-CHILD INTERACTIONS AT BEDTIME: A BIDIRECTIONAL ANALYSIS OF NONCOMPLIANT BEDTIME BEHAVIOR
\end{abstract}

by

Desiree J. Espinal

Florida International University, 2012

Miami, Florida

Professor Jacob Gewirtz, Major Professor

The purpose of this investigation was to (a) use the positive routines procedure to decrease child noncompliance and the time it takes the child to comply (latency) at bedtime, (b) to assess treatment fidelity, and (c) to record objectively parent behavior. Research was conducted with four children and five parents in their homes. The treatment was explained to each parent and introduced to each child after the baseline phase. Positive routines requires the parent to implement a low-stimulation "routine" at the time the child naturally gets sleepy. The routine gradually begins earlier so that by the end of treatment, it is completed at the time the parent originally attempted to establish bedtime. The data reveal that with high treatment fidelity, the treatment was effective in reducing bedtime noncompliance, latency, and parental reinforcing behaviors. The data also supported the notion that parent behavior can be controlled by child behavior. 


\section{TABLE OF CONTENTS}

CHAPTER

PAGE

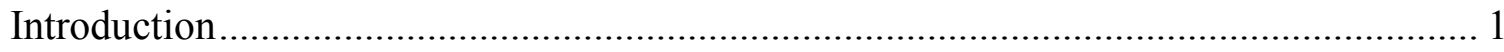

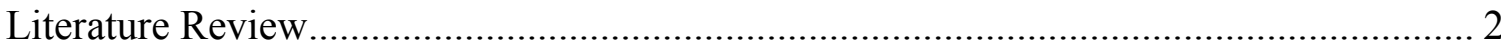

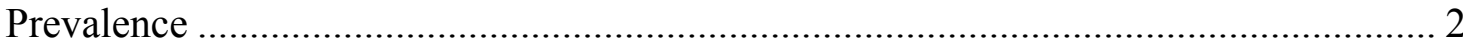

Impact of Sleep Problems on Child Development ......................................................... 3

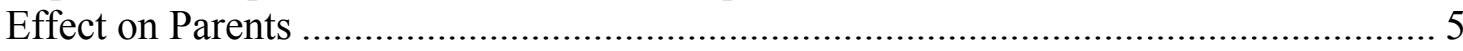

Traditional Unidirectional View of Child Development............................................... 5

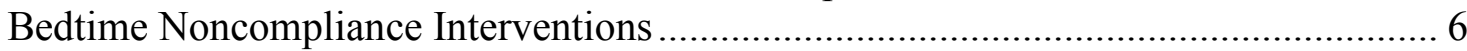

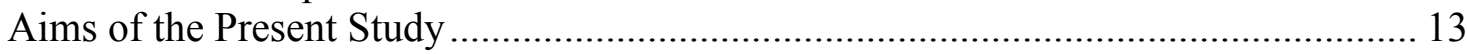

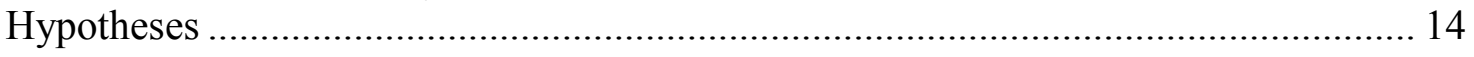

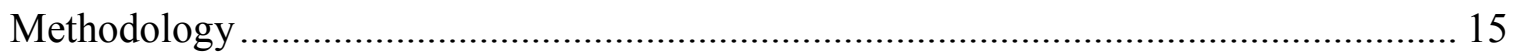

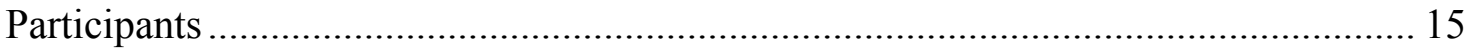

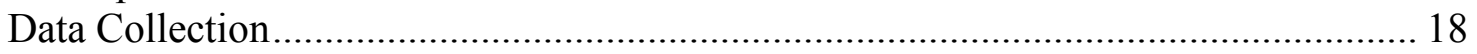

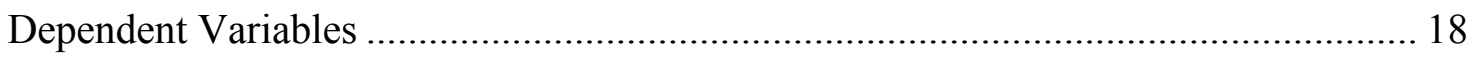

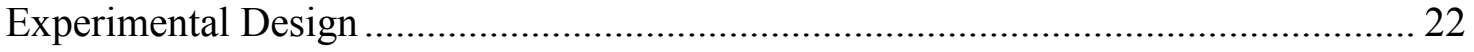

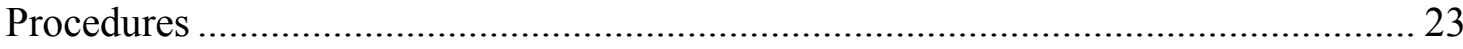

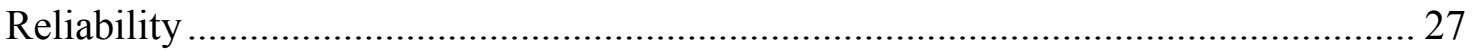

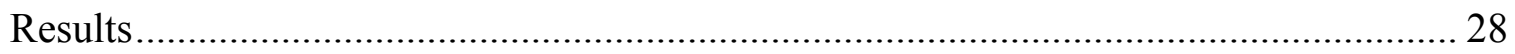

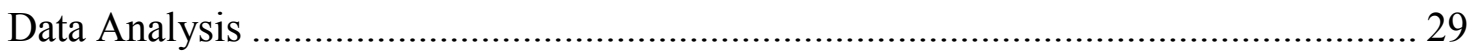

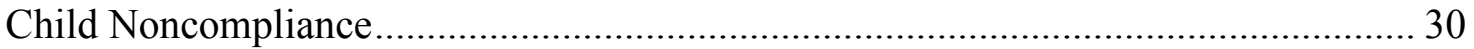

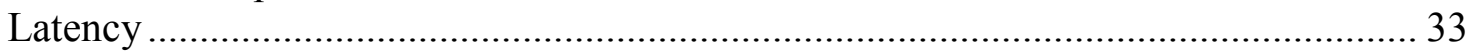

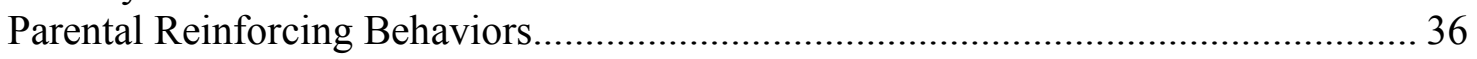

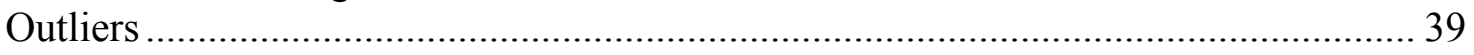

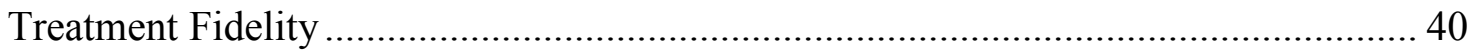

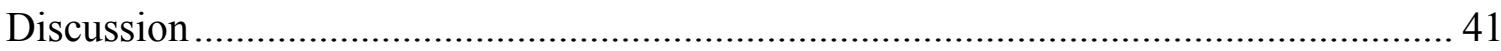

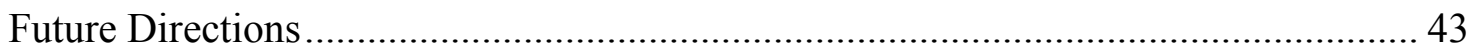

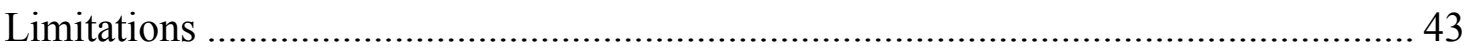

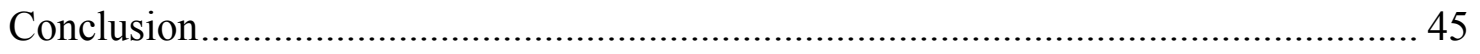

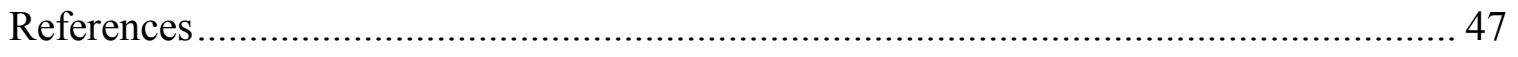

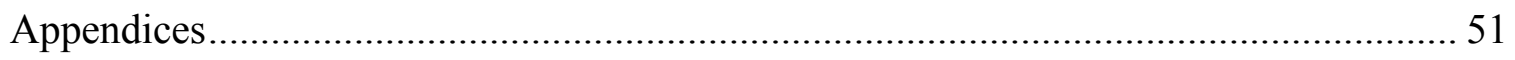




\section{Introduction}

For many parents, the task of putting their child to bed at night is often met with much resistance. Bedtime struggles are some of the most common childhood behavior problems (Kuhn, Mayfield, \& Kuhn, 1999). They are worth investigating because they are known to negatively impact children's developmental outcomes. Studies in which parents implement treatments to modify a child's behavior at bedtime are widely available in the literature. However, there are few studies demonstrating how changes in child behavior (as a result of treatment) directly influence the behavior of the caregiver. For example, extinction procedures, commonly used to reduce bedtime behavior problems, are often ineffective as parents may be unable or unwilling to ignore their children's crying episodes (Adams \& Rickert, 1989). A unidirectional view of the contingencies at play may lead to an incomplete view of noncompliant bedtime behaviors and, more generally, child development.

The present study had three primary purposes. The first was to use the positive routines procedure to decrease the frequency of noncompliant behaviors exhibited by the child at bedtime, as well as to decrease the time it takes the child to get in bed and remain quiet for at least 30 minutes once the parent has said "goodnight" (latency). The second purpose was to assess treatment fidelity and its relationship to treatment outcomes. The third, and most important purpose, was to contribute to the literature on childhood bedtime noncompliance, and in general to the literature on childhood development, by objectively recording the change in the parents' behavior as a function of the change in the children's behavior. Because sleep problems can be manifested in a number of ways, for the sake of this study, the researcher focused solely on bedtime refusal behaviors that 
delay sleep onset such as stalling, making excuses, leaving the bedroom, physical aggression (e.g., throwing objects, hitting), protests (arguing, crying, calling out), and ignoring the parent's instructions to go to sleep, or failing to respond within five seconds of the parent instructing the child to go to bed.

\section{Literature Review}

\section{Prevalence}

Meisbov, Schroeder, and Wesson (1993), and Richman, Stevenson, and Graham (1975), found that sleep related problems make parents "top ten" list of childhood behavior problems (as cited in Kuhn, Mayfield, \& Kuhn, 1999). The actual prevalence rate of childhood sleep disturbances varies widely across the literature because sleep problems have been operationalized in numerous ways. According to Mindell (1993), sleep problems include, but are not limited to, sleep talking, nightmares, waking at night, trouble going to sleep, enuresis, bruxism, sleep rocking, night terrors, restless sleep and bedtime refusal. The present study focused solely on bedtime refusal. These noncompliant behaviors were functionally defined as those which delay sleep onset such as: (a) stalling or making excuses or requests, (b) leaving the bedroom, (c) physical aggression (e.g., punching, throwing objects, hitting), (d) protesting (e.g., arguing, crying, calling out), and (e) ignoring parental requests, or failing to respond within five seconds of being instructed to go to bed. Blader, Koplewicz, Abikoff, and Foley (1997) asked 987 parents to report on their elementary school-aged children's sleep behaviors and reported that $27 \%$ of children exhibited bedtime refusal behaviors. An earlier study conducted by Salzarulo and Chevalier (1983) reported proportions as high as $42 \%$. Whatever the actual prevalence rate of children exhibiting bedtime noncompliance is, 
researchers have agreed that bedtime struggles are some of the most common childhood behavior problems. Examining the factors influencing these behavior problems is important because noncompliance at bedtime is known to negatively impact children's adaptive functioning and development.

\section{Impact of Sleep Problems on Child Development}

Currently, the literature suggests that, overall, sleep problems deserve more attention because of their high prevalence rates and the implications they have for future adaptive functioning. Many studies have found untreated sleep problems to be associated with childhood behavior problems (Adams \& Rickert, 1989; Ortiz \& McCormick, 2007; Wade, Ortiz, \& Gorman, 2007). Developmental psychologists often categorize problem behaviors as being either externalizing or internalizing. In the developmental literature, externalizing behavior problems refers to a group of problem behaviors exhibited by children aimed at their external environment (e.g., aggression), whereas internalizing behavior problems refers to problems that focus on a child's "internal psychological environment" (e.g., withdrawal; Liu, 2004). Although this distinction is not made by behavior analysts, the research on the impact of sleep problems on child development is found largely in the developmental literature.

Goodnight, Bates, Staples, Pettit, and Dodge (2007) concluded that there are definite links between insufficient sleep and externalizing behavior problems. Congruent with those findings, Lavigne et al. (1999) found that less nighttime sleep was associated with more externalizing problems on the Child Behavior Checklist in children between the ages of 2 and 5 years. Likewise, Gregory and O'Connor (2002) found that sleep problems at age four predicted parent-reported aggression later in adolescence and in a 
follow-up study, Gregory, Eley, O'Connor, and Plomin (2004) found sleep problems at age four to be predictive of mother-reported conduct problems at age seven. In line with the research correlating externalizing behavior problems and sleep problems, behavioral treatments for sleep problems have been found to reduce aggressive behaviors over time (Dahl, 1996), indicating that there is a strong relationship between externalizing behavior problems and sleep problems.

Sleep disturbances are also closely associated with other types of behavior problems as well (i.e, internalizing behavior problems). A literature review by Chorney, Detweiler, Morris, and Kuhn (2007), using the MEDLINE and PsychINFO computer databases, suggested a strong correlation between reported levels of sleep disturbances and behavioral problems associated with the clinical diagnoses of anxiety and mood disorders.

Lastly, a significant amount of research has also been conducted on the negative effects sleep disturbances have on academic performance. It is well known by cognitive and behavioral neuroscientists that sleep is fundamentally important for brain development, particularly learning (Dahl, 1996); therefore, it is not surprising that problems with learning are reflected in poor academic performance. Wade et al. (2007) pointed out that children may exhibit daytime sleepiness, impaired social functioning and poor school performance as a result of sleep disturbances. Moreover, Ravid, Afek, Suraiya, Shahar, and Pillar (2009) found that children who failed to meet the criteria for first-grade had significantly inferior sleep patterns compared to children who were eligible to move on to the first-grade. 


\section{Effect on Parents}

Although many studies have focused on how untreated sleep disturbances are associated with childhood behavior problems (Adams \& Rickert, 1989), few studies have investigated the profound negative effect these problems have on other individuals in the family. Some studies have found higher frequency of arguments between spouses, decreased levels of social and sexual activities, complaints of chronic fatigue, and reports of "maternal ambivalence" toward the child as a result a child's sleep difficulties (Wade et al., 2007). However, none of these outcome variables have been measured objectively like children bedtime behaviors have. In fact, Sadeh, Raviv, and Gruber (2000) note that one of the major limitations of the literature regarding sleep problems is the overreliance on subjective reports. In other words, there is a lack of studies examining parents' immediate and overt responses to their child's noncompliance at bedtime which are hypothesized to be under the control of the child's behaviors.

\section{Traditional Unidirectional View of Child Development}

A major trend present in studies investigating resistance to bedtime, sleep

disturbances and, more generally, child development is the obvious focus on the child's behavior and how the parent's behaviors affect their child's development. Gewirtz and Boyd (1977) make the case that traditionally, child development has been built on the one-sided assumption that the actions of the child's parents (or caretakers), are the principal and most fundamental environmental determinants of a child's development. Behavioral procedures have routinely shown that children's sleep difficulties may be related to how their parents interact with them at bedtime (Edwards \& Christophersen, 1994). The influence the child's behavior has on parental responding is often not 
discussed or thought to play a secondary role. This single-sided view is apparent in causal explanations for noncompliant bedtime behaviors, and especially in treatment options proposed to deal with them.

Despite the fact that studies in which parents implement procedures and treatments to modify a child's behavior are readily available in the literature, there are no studies objectively demonstrating how these positive results affect the behavior of the caregivers even while it is widely acknowledged that parental factors influence the outcomes of treatments. For example, parents are often unwilling to tolerate their child crying, thus making extinction an intervention difficult to implement (Adams \& Rickert, 1989). A unidirectional view of the influences affecting child development leads to an incomplete view of the contingencies at play.

\section{Bedtime Noncompliance Interventions}

There has been much interest in finding treatment methods parents can implement to reduce the frequency of child bedtime behavior resistance and sleep disturbances. According to Dougherty and Lane (1976), bedtime and night behavior problems are typically targets for extinction procedures.

Traditional extinction, or "systematic ignoring," involves terminating the reinforcement contingency that maintains a response resulting in a reduction of that behavior over time. Extinction produces long-lasting results but usually leads to extinction bursts, in which one or more dimensions of the behavior (e.g., frequency, intensity, duration) increases before abating (Cooper, Heron, \& Heward, 2007). Extinction is probably one of the clearest examples of how a child's behaviors affect parental responding. Adams and Rickert (1989) noted that parents may unintentionally 
reinforce bedtime tantrums. They observed that the ability of parents to ignore their child's crying episodes influence the effectiveness of extinction procedures. Naturally, mothers tend to respond to their child's cries, however, when maternal responding becomes contingent on the child's crying behavior, the crying behavior can be reinforced. Ironically, the behavior of the parent comes under the control of the behavior he or she was attempting to eradicate and their responses to the child's cries are reinforced by the termination of the child's cries (Gewirtz, 1976). The majority of adults will likely make an effort to stop crying in numerous ways because it has extremely powerful aversive qualities (Gewirtz, 1991). Some parents stay in the room and lay down with the child touching the child's back or quietly talking to the child until he or she falls asleep. Parents may also provide the child with pacifiers, bottles and food in bed and/or rock the child to sleep (Jencius \& Rotter, 1998).

It is interesting to note that Jencius and Rotter (1998) consider bedtime a type of ritual, in which the child separates from the parent to go to sleep, and bedtime resistance as "separation anxiety." Separation anxiety is the foundation of attachment theories. Rather than utilizing a hypothetical construct such as "attachment," the attachment concept was behaviorally defined by Gewirtz and Boyd (1977) as

a two-person, sequenced, mutual influence processes in which that individuals' responses comes under the control of discriminative stimuli provided by the appearance and responses of another person...thus, an attachment can be denoted by the occurrence of child responses under the control of stimuli from the attachment figure, and by the child maintaining proximity to that person. (p. 144) 
They note that during separation the stimulus response functions indicating attachment may become extremely disorganized resulting in intense emotional responding (i.e., protests). Gewirtz and Pelaez-Nogueras (1990) argue that these protests are accidentally conditioned early in life and maintained via contingent maternal behavior under the impression that they are being positive and "loving" mothers. This is perhaps why Adams and Rickert (1989) found that many parents viewed the extinction treatment as an unacceptable method to decrease noncompliant bedtime behaviors.

Research shows that parents play a major role in conditioning their infant's behavior. However, the fact that a child can condition the behavior of his/her parent is much less talked about. There exist damaging consequences if the mother (or primary caretaker) attempts to respond "lovingly," contingent upon a child's disruptive behaviors. By doing so, they may reinforce these maladaptive behaviors (e.g., bedtime noncompliance) resulting in a lower occurrence of more appropriate behaviors (e.g., compliance). These parents are less likely to use extinction with full compliance and may intermittently reinforce the protest behaviors they are trying to eliminate. As a result, many parents accidentally condition protest behaviors (Gewirtz, 1969) and do not ignore the bedtime crying behavior in their children long enough to complete the extinction procedure and see results (Adams \& Rickert, 1989).

Because parents are often unwilling to tolerate the child's crying behavior (Wade et al., 2007), and because many parents find the extinction technique unacceptable (Adams \& Rickert, 1989), alternative forms of treatment have been designed to handled childhood sleep disturbance and noncompliant bedtime behaviors including medication, graduated extinction (Ferber, 1985), the Bedtime Pass Program (BPP; Friman, Hoff, 
Schnoes, Freeman, Woods, \& Blum, 1999), and positive routines (Milan, Mitchell, Berger \& Pierson, 1981). However, the majority of these interventions have limitations.

Medication. Medications, such as antihistamines, chloral hydrate and melatonin, are commonly administered to children with sleep problems (Wade et al., 2007). Despite unwanted side effects, medication is used because, often times, it is easily administered. This has important implications when taking into account how the behavior of the child conditions the behavior of the parent. Because medication is easily administered and may result in more rapid results, many parents may use this form of treatment to handle their child's sleep disturbances. These medications are likely to sedate the child quickly and effectively.

Bedtime Pass Program. The Bedtime Pass Program (BPP; Friman et al., 1999) requires the child to get into bed where the parent then provides the child one "pass" to get out of bed or make a request to the parent; after the pass is used, the child must hand it over and any requesting or protesting responses thereafter are ignored. The BPP may lower the frequency of getting out of bed, but is not likely to eliminate the bedtime refusal behaviors entirely especially if these behaviors are not maintained by attention (Moore, Friman, Fruzzetti, \& MacAleese, 2007).

Graduated Extinction. Graduated extinction (Ferber, 1985) entails a reduction in parental attention to inappropriate bedtime behaviors until the child falls asleep. Parents briefly check in on their child after a few minutes and then leave the room and wait for a longer interval before they make a second check (Wade et al., 2007). However, if the protest responses are being maintained by parental attention the parent runs the risk of intermittently reinforcing the child's responses on a variable interval schedule, which 
ironically makes responses more resistant to extinction (Cooper et al., 2007). Parents may also be inadvertently reinforcing a higher intensity and longer duration of crying.

One limitation of all the above treatments is that parental attention is assumed to be maintaining protesting and resistant behaviors; but other factors may include termination of a preferred activity, for example. According to Cipani (1998), noncompliance may be maintained either by positive reinforcement or negative reinforcement. Positive reinforcement involves the delivery of a stimulus contingent upon a response that increases some dimension of that response (Cooper et al., 2007). For example, a parent remaining with his/her child until the child falls asleep is likely to be maintaining noncompliance under a positive reinforcement contingency.

On the other hand, negative reinforcement involves the removal of an aversive stimulus contingent upon a response that increases some dimension of that response (Cooper et al., 2007). Negative reinforcement can take the form of either escape or avoidance. In escape, the child (or organism, generally speaking) is in an aversive condition and exhibits a behavior that gets him/her out of that situation, strengthening that behavior in the future. For example, a parent taking the child out of bed after the child is in bed (aversive condition) screaming to get out is likely to be maintaining noncompliance under a negative reinforcement contingency (escape). The child is more likely to scream in order to escape bedtime in the future. In avoidance, the child is not yet in an aversive condition but exhibits behaviors that prolongs or prevents encountering the aversive condition. For example, a parent attending to a child's requests which delay sleep onset is likely to be maintaining noncompliance under a negative reinforcement contingency (avoidance). The child is more likely to make requests in order to avoid 
bedtime in the future. Most treatments designed to reduce bedtime noncompliance assume noncompliance is being positively reinforced. However, Wilder, Harris, Reagan, \& Rasey (2007) demonstrated, through a functional analysis, that noncompliance was more likely for two preschoolers when it resulted in termination of a preferred activity (negative reinforcement).

Positive Routines. The positive routines treatment (Milan et al., 1981) is a more promising alternative technique which entails the parent changing the child's bedtime to more closely coincide with when the child naturally falls asleep. Although this procedure does not work as rapidly as extinction, it is not as distressing to parents (Edwards \& Christophersen, 1994). Parents engage in a set of pre-bedtime activities, often incompatible with the target behavior of noncompliance, in which engagement in each constructive/appropriate activity is reinforced. Therefore, the positive routines procedure may be viewed as an extension of the differential reinforcement of incompatible behavior (DRI) paradigm or the differential reinforcement of alternative behavior (DRA) paradigm. Both paradigms have been found to be more favorable than traditional extinction because not only does it weaken the problem behavior, it simultaneously strengthens desirable behaviors that are either incompatible or an alternative to the targeted problem behaviors (Cooper et al., 2007). These two interventions have the ability to encourage the development of new skills (Cooper et al., 2007). Once the chain (i.e. routine) is established, bedtimes are systematically scheduled earlier so that, by the end of the treatment, the child is going to bed at his or her pre-established bed time. Though not as well-validated as extinction, at least four studies have found positive routines to be effective in the treatment of bedtime refusal (Adams \& Rickert, 1989; 
Galbraith \& Hewitt, 1993; Mattson, 1996; Milan et al., 1981) and each of the studies included some form of extinction (Moore, 2010). However, unlike traditional extinction, positive routines has a focus on the child developing sleep-compatible behaviors versus a sole focus on reducing inappropriate behaviors (Taylor \& Roane, 2010).

In the initial study conducted by Milan et al., (1981), three children with medical and/or intellectual disabilities, served as participants in the study evaluating the effectiveness of the positive routines treatment. Results showed: (a) improvement in preretirement cooperation (i.e., did the child cooperate when the parent initially told them to go to bed?), (b) a decrease in minutes past appropriate bedtime, and (c) a decrease in duration of in bed resistance. In a second study, Adams and Rickert (1989) assigned 36 children to one of three groups: positive routines, graduated extinction or control. The children in the positive routines and graduated extinction groups showed more improvement in behavior (i.e., less and shorter tantrums) at two follow-up observations three and six weeks after treatment than those children in the control group. Although both treatments were effective, parents in the positive routines group reported higher satisfaction with treatment than parents in the graduated extinction group. In a third study, parents of 45 children, ranging in age from 5-months-old to 6-years-old, reported an improvement in their child's bedtime compliance and less nighttime awakenings after the positive routines treatment was implemented (Galbraith et al., 1993). Lastly, in a dissertation comparing the natural sleep procedure (i.e., letting the child go to sleep whenever he/she is naturally sleepy) to the positive routines treatment, Mattson (1996) found that: (a) both procedures were effective in reducing tantrums at bedtime within a home setting in eight preschool children, and (b) the improvements in behavior observed 
during treatment were maintained at follow-up. Thus, research has repeatedly shown that the positive routines technique significantly improves the behavior of children at bedtime. Aims of the Present Study

The current study had three overarching goals. First, using the positive routines technique, the investigator aimed to decrease the time it took the child to go to bed after being instructed to do so (latency) and the children's frequency of bedtime noncompliant behaviors. Specifically, the researcher asked: what effects will the implementation of the positive routines treatment have on (a) the elapsed time between the parent telling the child to go to bed and the child complying (latency), and (b) the frequency of noncompliant behaviors exhibited by the child at bedtime? Second, the researcher aimed to evaluate the relationship between average treatment fidelity and treatment outcomes. Specifically, what is the relationship between treatment fidelity scores and (a) latency, (b) the frequency of child noncompliant behaviors at bedtime, and (c) parental engagement in reinforcing behaviors? Most importantly, the investigators hoped to close a gap in the literature by objectively recording the behavior of the primary caretaker as a function of child noncompliance and, in turn, shed light on how the child conditions the behavior of the parent. Specifically, the researcher asked: what effect will a decrease in the level of child noncompliance (as a result of the implementation of positive routines) have on the level of reinforcing behaviors the parent engages in at bedtime?

Because sleep problems can be manifested in a number of ways, in the present study, the researcher focused solely on bedtime refusal behaviors that delay sleep onset such as stalling, requesting or making excuses, leaving the bedroom, physical aggression (e.g., punching, throwing objects, hitting), protests (e.g., arguing, crying, calling out) and 
ignoring the parent's instructions to go to sleep, or failure to respond to instructions given by parents to go to bed.

\section{Hypotheses}

On the basis of studies indicating the effectiveness of positive routines as an effective treatment for bedtime refusal and noncompliance, it was hypothesized that if the positive routines treatment is correctly implemented by the parent, from baseline to treatment one should observe a marked decrease in: (a) the elapsed time between the parent telling the child "goodnight" and the child complying (latency), (b) the frequency of child noncompliant behaviors at bedtime, and (c) the percentage of reinforcing behaviors exhibited by the parent. On the basis of research demonstrating a bidirectionality of influences during parent-child interactions, it was hypothesized that if the frequency of noncompliant behaviors of the child decreases with treatment, the percentage of parental reinforcing behaviors (those maintaining and/or reinforcing child noncompliance) will have decreased at follow-up when compared to baseline. Moreover, it was hypothesized that parents who maintain, on average, higher levels of treatment fidelity during the treatment phase will observe more of an improvement in their child's behavior and will be less likely, at follow-up, to engage in the reinforcing behaviors that once maintained their child's noncompliance.

A reduction in parental reinforcing behaviors as a result of a decrease in (a) the elapsed time between the parent instructing the child to go to sleep and the child complying (latency), and (b) the frequency of child noncompliance would support the notion of bidirectional interactions occurring at bedtime between the child and the parent, strengthen the notion that parents' behaviors are often influenced by the behavior of their 
children. Acknowledging the two-way interactions between parents and their children allows for a clearer understanding of the maintenance of child behavior problems.

\section{Methodology}

\section{Participants}

Four typically developing children (ranging in age from 4 to 7 years old) and their parents served as participants for this study. One child had both parents participate in the study. Parents were recruited in two ways: (a) via flyer advertisements given to them when they picked up or dropped off their child from daycare or (b) via word of mouth from other people who had seen the flyer advertisements in pediatricians offices and/or preschools. Flyers were distributed at pediatrician offices, daycares and preschools in Miami-Dade County, Florida (see Appendix D). All four children came from Hispanic families. Approximately $65 \%$ of persons living in Miami-Dade County are persons of Hispanic or Latino origin (Family Structure \& Poverty, 2008). All parents indicated that their child exhibited bedtime noncompliant behaviors four or more nights during a typical school week. Bedtime noncompliance took many forms such as stalling or making excuses to delay sleep onset, leaving the room, physical aggression (e.g., throwing objects, hitting, punching), protests (e.g., arguing, crying, calling out), and ignoring or failing to respond within five seconds of the parent's instructions to go to bed. Parent reports of these behaviors were supported by observations made during the baseline phase of the study. A brief description of each participant follows (all names are fictitious).

Lucy was a 4-year-old girl living with her mother, father and older brother. The child's older brother was usually asleep by the time she was put to bed. Lucy's mother 
was responsible for putting her to bed at night. Therefore, only her mother participated in the study. When Lucy's mother attempted to put her in bed, she would initially comply. However, as her mother would attempt to leave the room, Lucy would request snacks and drinks, ask her mom to allow her to sleep in the "big bed" (her parent's bed), or tell her mom that she was "not good at sleeping." Often, Lucy would cry and get out of bed. If the mother did not comply with her child's request, Lucy's father would sometimes intervene and give in. During the pre-experiment phase, Lucy's mother reported that both her and her husband would take turns patting Lucy on the back until she finally fell asleep in her own bed.

Gabriel was a 4-year-old boy living with his mother and father. At bedtime, Gabriel's father was rarely home from work; therefore, it was Gabriel's mother who was responsible for putting him to bed. When his mother attempted to do so, he would whine and ask her to stay in his room with him because he was scared. Whining was defined as speaking in a nasally manner at a pitch higher than usual. If Gabriel's mother attempted to leave the child alone in the bedroom, he would cry and the mom would promptly return to attend to his cries. Every night during baseline, the mother would stay in the room and lay down next to her child until he fell asleep. While the mother lay next to him, he would engage her in conversation, which delayed sleep onset even more.

Bryan was a 6-year-old boy living with his mother and father. Both parents took turns putting him to bed during the study. When his mother attempted to put him to bed, he would become very playful and complain that he was not sleepy. He would engage his mother in conversation, delaying sleep onset. Often he would ask his mother if he could sleep in her bed and explain that he just wanted someone to cuddle with. Most 
nights, he would settle for his mother staying in his bedroom with him a little longer until he fell asleep. When his father would put him to bed, he would become very playful and conversational. He constantly engaged his father in conversations about school or movies. On most days Bryan's father would interact back for some time before leaving the room entirely or he would stay in the room for one or two songs before exiting. Both parents allowed the child to listen to calming music when going to sleep.

Enzo was a 7-year-old boy living with his mother, father and baby sister. The child did not share a room with his sister and his sister was usually asleep by the time Enzo's mother sent him to bed. When instructed to go to sleep, he would ask his mom for snacks or for permission to watch television. Sometimes, he would ask his mom if he could sleep with his baby sister in his parent's room because he was scared.

Participants had no history of psychological disorders, medical disorders or developmental delays. None of the children were taking medications for sleep at the time the study took place. Children sharing bedrooms with siblings and/or living with nonnuclear family members (e.g., grandparents, aunts, or uncles) were not included in the study because additional persons in the home are likely to affect parent-child interactions. A verbal, 10-item quiz was given to parents before the start of the treatment phase in order to determine if they had read and understood the intervention procedures (see Appendix B). All four parents included in the study passed the quiz with a score of $90 \%$ or higher. At the start of the study, none of the families expected major lifestyle changes or had planned vacations in the time the study was to take place. However, unexpected events did occur. Lucy's family decided to go on vacation for four days during the treatment phase (Thursday through Monday), and between the treatment phase and the 
follow-up phase, Gabriel's parents separated. For Bryan, his father's job required him to go away for days at a time and his mother started attending school in the time between treatment and follow-up.

\section{Data Collection}

All of the child participants attended school, therefore, data collection took place Sunday through Thursday (the nights before school days). Data were collected using audio-recorders (Spy Ear Bug Audio Voice Recorder USB Flash Drive 2GB). The audiorecorders were flash drives that could be plugged into computers for file transfers. Each recorder had a switch on the side, which could be switched "on" to begin a recording or "off" to end a recording. Once the recorder was turned on, a red light would flash three times to indicate it was charged and recording properly. If the red light did not flash, the recorder was either broken or not charged. Each recorder could be charged by plugging it into a computer that was turned on.

Parents were given two audio-recorders. One recorder was to be with them at all times and the other was placed in the child's room. Parents were instructed to turn on both recorders about one minute before instructing their child to go to bed (baseline) or

starting the bedtime routine (treatment) and to turn them off thirty minutes after the child had been in bed and quiet for at least thirty minutes (or after they knew for sure their child was asleep). Nightly audio-recordings were then sent electronically to the experimenter by 9:00 am the next day. The recordings were transcribed daily.

\section{Dependent Variables}

Child. Using the transcripts of the audio-recordings, research assistants took data on latency, or the elapsed time between the parent saying "goodnight" to the child 
(baseline) or the routine ending (treatment and follow-up) and compliance. Compliance was deemed when the child was in bed and quiet for at least 30 minutes. Data were also collected on (b) the frequency of bedtime noncompliant behaviors emitted by the child during three phases: (a) baseline, (b) treatment, and (c) follow-up. Bedtime noncompliant behaviors included the following behaviors taking place immediately after the parent instructs the child to go to sleep: stalling, requests or making excuses to delay sleep onset, leaving the bedroom, physical aggression (e.g., punching, hitting or throwing objects), protests (e.g., arguing, crying and calling out), playing, as well as ignoring, or failure to respond to, the parent's instructions within five seconds.

Operational Definitions of Child Noncompliance. Stalling was operationally defined as engaging the parent in conversation unrelated to sleep, making requests, or making invalid excuses. Requests ranged from asking for snacks and drinks to asking the parent for permission to play a game or turn on the television. Leaving the bedroom or getting out of bed was operationally defined as getting up from the bed and exiting the bedroom in which the child normally sleeps. Therefore, "leaving the bedroom" or "getting out of bed" was counted when parents would verbally say "what are you doing out of your room?" or "why are you out of bed?" Physical aggression, such as punching, hitting or throwing objects, was defined by the child using any of their body parts (e.g., arms or legs) or any external object to strike their parent or anything else in their environment. Pushing was also considered physical aggression. Like getting out of bed and leaving the room, these behaviors were determined largely by verbal cues made by the child or parent (e.g., one parent mentioned "why are you pushing me?"). These behaviors were also determined by sounds made in the bedroom while the child was 
protesting (e.g., "thud"). Protests, such as crying, calling out, arguing, whining, moaning and groaning) were determined by sounds made by the child. Crying, whining, moaning, and groaning were defined as uttering or making inarticulate sounds, usually in a pitch louder or lower than typical speech. Because crying is better measured by duration, rather than frequency, a break of five seconds or more between crying sounds were counted as different instances of crying. Arguing was operationally defined as refusal by saying "no" or yelling at the parent. Calling out was defined as the child yelling "mom!" or "dad!" from inside the room when the parent was outside of the bedroom. Playing was defined as constant giggles, singing, and laughter unprovoked by the parent. The parent would often say "stop playing around." Lastly, ignoring was defined as the child failing to respond within five seconds of instructions delivered by the parent to go to bed. Ignoring was determined when the parent would repeat the child's name or say something along the lines of "did you hear me?" or "excuse me, I'm talking to you."

Parent. Using the transcripts of the audio-recordings, the frequency of behaviors immediately following bedtime noncompliance thought to be reinforcing the child's noncompliance at bedtime during the baseline, treatment, and follow-up phases of the study was recorded. The frequency of reinforcing behaviors per night was then divided into the total number of opportunities to reinforce (i.e., the number of noncompliant behaviors exhibited by the child that same night). Each parent was expected to engage in varying "reinforcing behaviors." Research shows that bedtime noncompliance is typically maintained by positive reinforcement, negative reinforcement, or both. Because of a lack of resources, the assumption was made that bedtime noncompliance for each 
child in the study was being maintained by both. Even if one particular child's behaviors were only being maintained by one of the two, the positive routines treatment used in the present study targeted both functions simultaneously. The sleep interview (see Appendix B) conducted before baseline began was used to shed light on the behaviors each parent was evoking that were likely reinforcing and maintaining their child's bedtime refusal behaviors. Moreover, during the treatment phase of the study, treatment fidelity was assessed by comparing the parent's behaviors to the procedural guidelines of the positive routines treatment.

Positive routines has five major treatment guidelines. The parent must (a) observe the child for signs of sleepiness (e.g., yawning, closing eyes; SS), (2) cease stimulating activities and interactions with the child (CSAI), (3) implement a routine (IR), (4) reinforce completion of each activity in the routine (RAC), and (5) reinforce getting into bed with a bedtime story and/or praise (BSP). Treatment fidelity was evaluated daily. If the parent followed five out of the five guidelines, they received a score of 5 (high fidelity). Following four, three, two or one of the guidelines warranted a score of $4,3,2$, and 1 , respectively. If the parent did not follow any of the guidelines on a given night, they received a score of 0 (no fidelity).

Operational Definition of Parental Reinforcing Behaviors. Because it is widely acknowledged that noncompliant behaviors at bedtime are likely maintained by both negative and positive reinforcement, attention, escape, or avoidance contingent on any instance of bedtime noncompliance was counted as an occurrence of parental reinforcing behavior. Common examples from the present study included providing attention to protests in the form of re-entering the child's bedroom, "shhh"-ing the child or trying to 
"reason" with the child, patting the child on the back or laying with the child until the he/she stopped protesting and went to sleep, giving into requests for longer bedtime stories, and engaging in a conversation, initiated by the child, unrelated to bedtime.

Operational Definition of Treatment Guidelines. As previously stated, the positive routines treatment has five major guidelines. The first is to observe the child for signs of sleepiness (SS). Sleepiness was determined by observers if the child was heard yawning, verbally expressing that they were tired and wanted to go to sleep, or if the parent verbally mentioned that the child was tired. The second guideline is the ceasing of stimulating activities and interactions with the child (CSAI). Cessation of stimulating activities and interactions was determined by observers if the television and all gaming systems were off and the parent did not engage the child in conversation unrelated to sleep. The third guideline was to implement a routine (IR). Each child had a different routine. If the routine was comprised of low-stimulating activities, the point was given for this guideline. Examples of low-stimulating activities include, but are not limited to, a warm bath, teeth-brushing, or drinking a warm glass of milk. The fourth guideline was to reinforce the completion of activities (RAC) in the routine with praise. For example, the parent says: "nice job brushing your teeth." The fifth and final guideline was reinforcing getting into bed with a bedtime story and/or praise (BSP).

Experimental Design

Changes in the children's and parents' behavior over time was assessed using a delayed multiple baseline across participants design, a variation of the traditional multiple baseline design (Baer, Wolf, \& Risely, 1968). According to Baer et al. (1968), multiple baselines are single subject designs used when reversing a behavior is undesirable. In the 
present study, reverting back to high levels of bedtime noncompliance would have been objectionable, particularly to the parents. Caretakers may have been unwilling to withdraw treatment and return to baseline levels of noncompliance if the treatment had been effective. In a delayed multiple baseline design initial baseline and intervention are begun and subsequent baselines are added in a staggered or delayed fashion (Cooper, Heron, \& Heward, 2007). The delayed multiple baseline design was used in order to prevent attrition. Traditional multiple baseline designs oblige some of the participants to remain in baseline (without treatment) for a longer period of time than others. Therefore, it was best to start baseline for each individual in a staggered fashion. Each participant had six (or five in one case) days of baseline. Three days into each participant's baseline, the next participant began baseline. The staggering allowed for overlapping baselines (a necessary criterion of multiple baseline designs) but did not force some participants to remain in baseline (B), without treatment (T), for a longer time than others.

\begin{tabular}{|c|c|c|c|c|c|c|c|c|c|c|c|c|c|c|c|}
\hline Session & 01 & 02 & 03 & 04 & 05 & 06 & 07 & 08 & 09 & 10 & 11 & 12 & 13 & 14 & 15 \\
\hline Participant1 & B & B & B & B & B & $\mathrm{T}$ & $\mathrm{T}$ & $\mathrm{T}$ & $\mathrm{T}$ & $\mathrm{T}$ & $\mathrm{T}$ & $\mathrm{T}$ & $\mathrm{T}$ & $\mathrm{T}$ & $\mathrm{T}$ \\
\hline Participant 2 & & & $\mathbf{B}$ & $\mathbf{B}$ & $\mathbf{B}$ & $\mathbf{B}$ & $\mathrm{T}$ & $\mathrm{T}$ & $\mathrm{T}$ & $\mathrm{T}$ & $\mathrm{T}$ & $\mathrm{T}$ & $\mathrm{T}$ & $\mathrm{T}$ & $\mathrm{T}$ \\
\hline Participant 3 & & & & & $\mathbf{B}$ & $\mathbf{B}$ & $\mathbf{B}$ & $\mathbf{B}$ & $\mathbf{B}$ & $\mathrm{T}$ & $\mathrm{T}$ & $\mathrm{T}$ & $\mathrm{T}$ & $\mathrm{T}$ & $\mathrm{T}$ \\
\hline Participant 4 & & & & & & & $\mathbf{B}$ & $\mathbf{B}$ & $\mathbf{B}$ & $\mathbf{B}$ & $\mathbf{B}$ & $\mathrm{T}$ & $\mathrm{T}$ & $\mathrm{T}$ & $\mathrm{T}$ \\
\hline
\end{tabular}

Table 1. Delayed multiple baseline design

Procedures

Children and their parents contributed data over two months (non-consecutively) to this study assessing the bidirectional influences between parent and child at bedtime. The study consisted of four phases: (a) pre-experiment phase, (b) baseline phase, (c) 
treatment phase, and (d) follow-up phase. Baseline for each family lasted five to six days. Because a delayed multiple baseline design across participants was used, the experimenter collected two weeks of baseline data in total for all four families. The treatment phase lasted about four to five weeks for each family. The last treatment session for the last participant took place before schools closed for holiday break. Follow-up took place approximately two and a half months after the last treatment session and lasted one week.

Pre-experiment. The experimenter met with parents recruited for the study. During the meeting, parents were asked questions regarding their eligibility to participate in the study. Parents were interviewed and asked questions from both the Child Sleep Assessment (Jencius \& Rotter, 1998) and the Semistructured Interview of Children's Sleep Disturbance (Kuhn et al., 1999; see Appendix B). They were asked to report on the history of their child's current sleep problems and provide descriptions (e.g., number of nights the child engages in bedtime noncompliance during a typical week, what types of noncompliance behaviors the child exhibits). Questions regarding how parents respond to these behaviors were included in the interview as well. Furthermore, the investigator inquired about developmental, psychological, and medical history (including medications). Lastly, the sleep interview also included questions regarding bedtime habits and routines, desired versus actual bedtime, the child's sleep environment, and the child's behavioral signs of sleepiness.

After determining eligibility, parents were briefly explained how the Positive Routines treatment works and of its known effectiveness. Parents were be explained that data would be collected using audio recorders and that they would be required to send the 
experimenter the recordings from the night before by 9:00 am the next morning via electronic mail. Next, they were presented with the informed consent form (see Appendix A) and asked to sign if they agreed to participate in the study. They were made aware of confidentiality agreements and informed that if at any moment they wished to discontinue, they could. Parents were told that the purpose of the study was to investigate environmental factors involved in bedtime resistant behaviors and to decrease the time it takes their child to go to sleep, as well as the frequency of bedtime noncompliance behaviors over time.

Baseline. During this phase of the experiment, parents were told that they should continue doing whatever they normally do when their child does not comply at bedtime and that treatment would be provided if no improvement was observed in their child's behavior. Data were taken on the child and the parent. In regards to the child, the time it took the child to go to bed after being instructed to do so (latency) and the frequency of noncompliant behaviors were recorded. Research assistants focused solely on bedtime refusal behaviors (e.g., stalling, making requests or making excuses, leaving the room, physical aggression, protests, and ignoring) following the parent instructing the child to go to bed. Additionally, data were taken on the caretaker's response to these noncompliant behaviors. The frequency of parent behaviors immediately following bedtime noncompliance and thought to be reinforcing the child's resistance behaviors was also gathered from the audio recordings.

Treatment. Treatment was introduced after five to six days of baseline data were collected. Since data were not being collected over the weekend (Friday and Saturday night), the experimenter instructed parents not to enforce bedtime on these days before 
the treatment phase began and to make note of the time their child naturally fell asleep. Using these notes and baseline data, the researcher selected ideal starting bedtimes for each child, on the basis of when he or she naturally fell asleep.

On the first day of treatment, parents were given specific instructions on how to implement the positive routines treatment. Parents were instructed to construct a "positive routine" from four to six low-stimulating activities lasting no longer than a total of 20 minutes. The experimenter provided the parents with examples. Parents were told to praise their child after completion of each activity in the routine in order to prevent possible noncompliance with these activities in the future. At the completion of the activities, parents instructed their child to go to sleep. If at any time after the completion of the routine the child began to engage in noncompliant behaviors, the parent was to place the child back in bed, saying firmly, securely and with minimum affect, "The routine is over; it is time for bed." After three days of compliance, the routine began 5 to 10 minutes earlier so that by the last week of treatment, the routine was completed at the time the parent(s) had originally attempted to establish as bedtime. Next, the parents were then given a verbal 10-question quiz in order to ensure that they completely understood the intervention (see Appendix B).

During this phase of the experiment, just as in baseline, data were taken on both the child and the parent. The child's frequency of noncompliant behaviors and the time it took the child to go to bed after being instructed to do so (latency) was recorded, as well as, the frequency of "reinforcing behaviors" the parent emitted in response to the child's noncompliance. Additionally data were taken on parent treatment fidelity. A score of 0 to $5(0=$ no fidelity; $5=$ high fidelity $)$ was assigned depending on how many of the five 
treatment guidelines were followed nightly. At the end of the treatment phase, parents were reminded that the experimenter planned to follow up on their child's progress in two and a half months.

Follow-up. Follow-up data were gathered about two and a half months after the last intervention session. All participants participated at follow-up. At this time, parents resumed data collection as before. Parents were not told whether to continue implementing the routine or not.

Debriefing. At the end of the study, parents were informed that data were also taken on their responses to their child's noncompliance and the purposes for doing so. Parents were told that it was necessary to take data on the primary caregiver's behavior to shed light on the behaviors they evoke that are likely inadvertently reinforcing and maintaining their child's bedtime refusal behaviors. Moreover, it is a primary goal of the study to understand how the child's behaviors influence parenting. The investigator informed the parents that behavioral difficulties, such as bedtime noncompliance, could result from misplaced contingencies provided by the parent (or other caregivers) in response to their child's problematic or inappropriate behaviors (Gewirtz \& PelaezNogueras, 1993). Acknowledging the reciprocity in behavioral problems and in procedures to eliminate them provided a foundation for understanding parent-child interactions and child development.

\section{Reliability}

Parent-child interactions during the baseline, treatment, and follow-up phases were transcribed using the nightly audio recordings. A frequency count of child's noncompliance and parent's reinforcing behaviors, as well as fidelity scores, were 
assessed by independent observers. The percentage of reinforcing behaviors exhibited by the parent were calculated by dividing the number of times the parent reinforced an instance of noncompliance by the number of times the child did not comply (opportunities to reinforce) and multiplying it by 100. Interobserver agreement (IOA) for frequency of child noncompliance and parent reinforcing behavior was calculated for each participant by dividing the smaller total by the larger and multiplying it by 100 .

Reliability observations were conducted during baseline, treatment, and follow-up on $33 \%$ of sessions for each participant. Mean interobserver agreement for Lucy was $85.7 \%$ (range, 80.0-93.8) and 86.1\% (range, 80.0-100.0) for her parent. Mean interobserver agreement for Gabriel was 87.8\% (range, 80.6-97.6) and 88.8\% (range, 80.5-97.3) for his parent. Mean interobserver agreement for Bryan was $88.8 \%$ (range, $80.0-100.0$ ) and $83.8 \%$ (range, 80.0-91.8) for his father and $88.1 \%$ (range, $83.3-98.3$ ) for his mother. Mean interobserver agreement for Enzo was 92.0\% (range, 80.0-100.0) and 92.6\% (range, 81.5-100.0) for his parent.

Treatment fidelity was given a score of 0 to 5 for each treatment and follow-up session. Interobserver agreement (IOA) for treatment fidelity was calculated for each parent by dividing the number of agreements by total number of treatment and follow-up sessions and multiplying it by 100. Interobserver agreement scores for Lucy’s parent, Gabriel's parent, Bryan's parents and Enzo's parent were 84.2\%, 92.3\%, 84.2\%, and $88.2 \%$, respectively.

\section{Results}

The goals of the current study were: (a) to use the positive routines procedure to decrease the children's frequency of bedtime noncompliance and the time it takes the 
child to comply, (b) to assess the role of treatment fidelity, and (c) to objectively record the behavior of the parent as a function of their child's compliance and noncompliance. The latter goal is fundamental in closing a gap in the literature by shedding light on the reciprocal interactions between parent and child at bedtime.

Five general hypotheses were formulated. First, the implementation of positive routines will result in a decrease in the frequency of noncompliant behaviors exhibited by the child at bedtime. Second, the implementation of positive routines will result in a decrease in the elapsed time between the parent saying "goodnight" and the child being quiet and in bed (latency). Third, the higher the parent's average treatment fidelity score, the bigger the improvement he/she will observe in their child's behavior; fidelity scores will be positively correlated with the magnitude of change in the level of the child's noncompliance at treatment and follow-up when compared to baseline. Fourth, the higher the parent's average treatment fidelity score, the bigger the change in the percentage of noncompliant behaviors they reinforced during treatment and follow-up when compared to baseline; once positive routines is introduced, higher fidelity scores should result in the parent reinforcing their child's noncompliance less. Fifth, as the frequency of noncompliant behaviors exhibited by the child decreases, the level of reinforcing behaviors exhibited by the parent, which were once maintaining and/or reinforcing child noncompliance, will also decrease.

Data Analysis

The theoretical question posed in this study was best analyzed by visual analysis of line graphs and correlational analyses. Behavior analysts use visual analysis to interpret graphically displayed data (Cooper et al., 2007). Visual analysis answers two 
questions: (a) did significant behavior change occur? and (b) if so, how much of the change was caused by the independent variable? (Cooper et al., 2007). Visual analysis within conditions was conducted to determine behavioral variability, level of performance and the direction and degree of trends in the data.

Line graphs are the most commonly used format for the graphic display of behavioral data (Cooper et al., 2007). The horizontal axis represents the passage of time (i.e., the session number) and the presence or absence of the independent variable (i.e., the positive routines treatment). Each night is equivalent to one session. In a week there are five sessions: Sunday, Monday, Tuesday, Wednesday, and Thursday night. The vertical axis represents a range of values of the dependent variables (e.g., frequency of the target behavior). In the current study, each point on the graph shows the frequency, latency, or percentage of a target behavior in relation to an experimental condition (e.g., implementation of positive routines).

\section{Child Noncompliance}

The frequency of noncompliant behaviors exhibited by the child participants during the baseline, treatment, and follow-up phases of the experiment are presented in Figure 1.

The frequency of noncompliance decreased from baseline to treatment in all cases, but one. Although Lucy and Enzo each experienced one night of unusually high levels of noncompliance, session 9 and 19 respectively, in general, both children maintained low levels of noncompliance once treatment was introduced. From baseline to treatment, Lucy and Enzo demonstrated a $71.2 \%$ and $76.7 \%$ decrease in average noncompliant behaviors, respectively, and a $79.5 \%$ and $85.8 \%$ decrease in average 


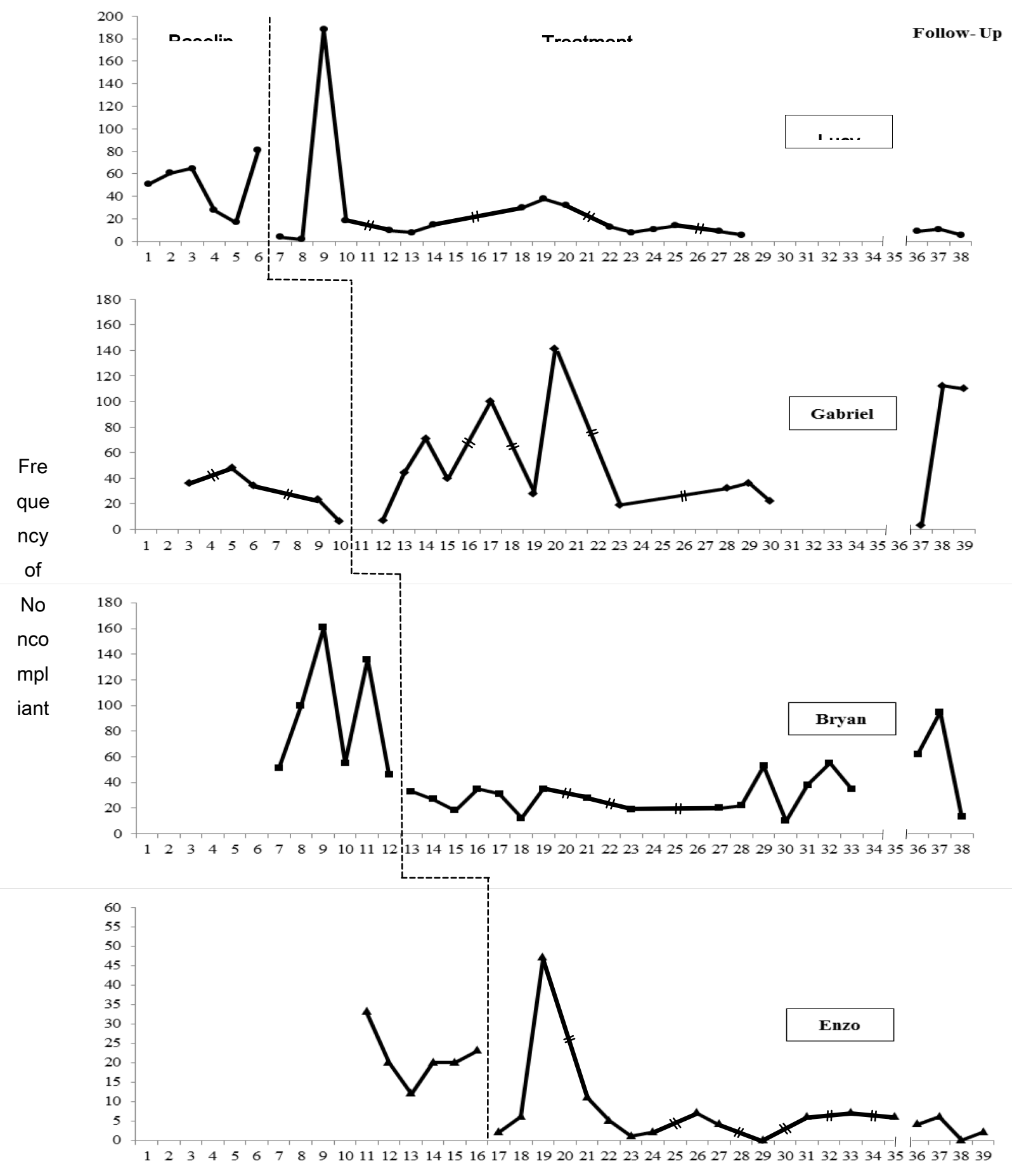

Figure 1. Frequency of noncompliant behaviors exhibited by child participants during the three phases of the experiment: (a) baseline, (b) treatment, and (c) follow-up. 
noncompliant behaviors, respectively, from baseline to follow-up. The second child participant, Gabriel, did not experience noticeable improvement in his behavior when comparing his average level of noncompliance in baseline to his average level of noncompliance in the treatment phase. In fact, the data show that Gabriel's behavior worsened when treatment was initially implemented and subsequently returned to baseline levels toward the end of the treatment phase. Later analysis of his parent's treatment fidelity scores throughout the study shed some light as to why Gabriel's behavior did not improve and in fact, worsened. Moreover, the downward trend observed at the end of Gabriel's baseline phase is explained further with his latency results. For Bryan, baseline data appears to be highly variable; however, unlike the other children, both of his parents took turns putting him to bed at night. On the first, fourth and five nights of baseline, his father was responsible for putting him to bed and on the second, third and sixth night of baseline his mother was. Taking this into account, baseline data within parents is quite stable. Once treatment was implemented, Bryan's behavior showed improvement regardless of which parent was responsible for putting him to bed. When being put to bed by his father, Bryan demonstrated a $52.0 \%$ decrease in average noncompliant behaviors from baseline to treatment and a $74.3 \%$ decrease in average noncompliant behaviors from baseline to follow-up. When being put to bed by his mother, Bryan demonstrated a $75.2 \%$ decrease in average noncompliant behaviors from baseline to treatment and a $40.7 \%$ decrease in average noncompliant behaviors from baseline to follow-up. The hypothesis that the implementation of the positive routines procedure would decrease the frequency of noncompliant behaviors exhibited by the child was supported in three of the four cases. 


\begin{tabular}{|c|c|c|c|c|c|}
\hline Participant & Baseline & Treatment & Follow-up & $\begin{array}{c}\text { Baseline to } \\
\text { Treatment }\end{array}$ & $\begin{array}{c}\text { Baseline to } \\
\text { Follow-up }\end{array}$ \\
\hline Lucy & 50.5 & 14.6 & 8.7 & $\begin{array}{c}71.2 \% \\
\text { decrease }\end{array}$ & $\begin{array}{c}79.5 \% \\
\text { decrease }\end{array}$ \\
\hline Gabriel & 29.4 & 40.1 & 111.0 & $\begin{array}{c}67.0 \% \\
\text { increase }\end{array}$ & $\begin{array}{c}277.6 \% \\
\text { increase }\end{array}$ \\
\hline $\begin{array}{c}\text { Bryan } \\
\text { (with dad) }\end{array}$ & 50.7 & 24.3 & 13.0 & $\begin{array}{c}52.0 \% \\
\text { decrease }\end{array}$ & $\begin{array}{c}74.3 \% \\
\text { decrease }\end{array}$ \\
\hline $\begin{array}{c}\text { Bryan } \\
\text { (with mom) }\end{array}$ & 132.3 & 32.8 & 78.5 & $\begin{array}{c}75.2 \% \\
\text { decrease }\end{array}$ & $\begin{array}{c}40.7 \% \\
\text { decrease }\end{array}$ \\
\hline Enzo & 20.8 & 4.8 & 3.0 & $\begin{array}{c}76.7 \% \\
\text { decrease }\end{array}$ & $\begin{array}{c}85.8 \% \\
\text { decrease }\end{array}$ \\
\hline
\end{tabular}

Table 2. Average frequency of noncompliance and percent changes across phases for each child.

Latency

The amount of time (in minutes) that it took each child to comply with their parent's instruction to go to sleep during the baseline, treatment, and follow-up phases of the study is shown in Figure 2. Because routines varied across participants, latency data for Lucy, Gabriel and Enzo was calculated from the time the parent finished reading their child a bedtime story to the time that the last verbal sound made by the participant or parent on each night's recording. Latency data for Bryan was calculated from the time the parent finished the bedtime prayer to the time that the last verbal sound was made by the participant or the parent on each night's recording. Parents were instructed to turn off the recorders after their child had been in bed and quiet for more than 30 minutes because the assumption was made that the child would be asleep.

In general, latency appeared to decrease across participants once the positive routines treatment was implemented; however, some of the children experienced interesting trends. Initially, it appears that Lucy and Gabriel's latency began to decrease 


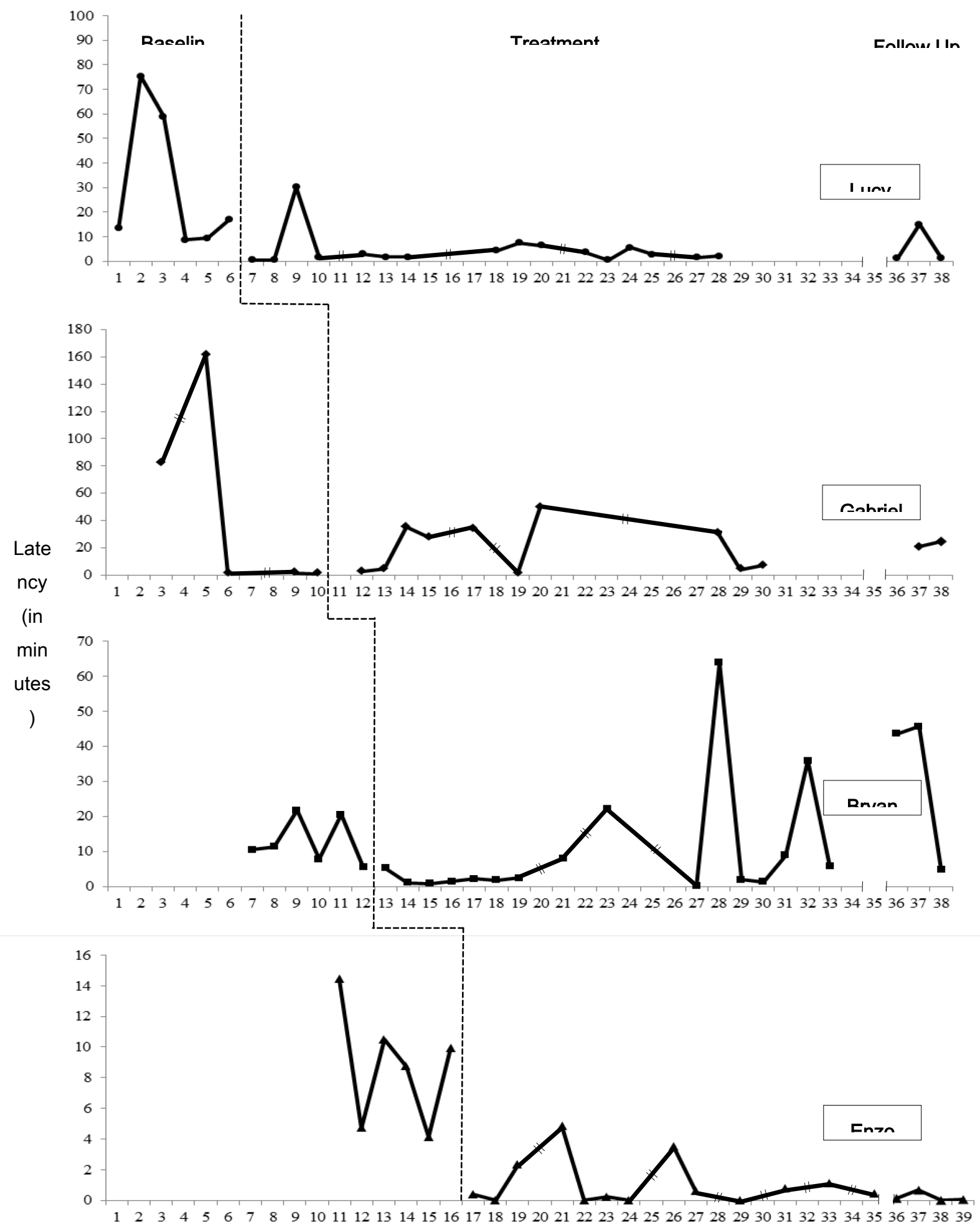

Figure 2. Latency data from the three phases of the experiment: (a) baseline, (b) treatment, and (c) followup. 
during baseline before positive routines was introduced. However, for Lucy's baseline days four and five, the child had developed a fever which likely contributed to shorter latency scores. Additionally, the last two days of baseline data for Gabriel, his mother allowed him to watch television for over an hour until he got sleepy. Therefore, by the time the child was instructed to go to sleep, it was already very late and he was already sleepy. Towards the end of Bryan's treatment phase, particularly sessions 28 and 32, latency scores became more variable. During session 28 , the child indicated that he was scared to sleep alone because he had experienced a nightmare the night before. During session 32, Bryan's mother did not follow any of the positive routines treatment guidelines and received a fidelity score of 0 . Nevertheless, latency appeared to decrease after the implementation of the positive routines procedure for all four children. From baseline to treatment, Lucy, Gabriel and Enzo demonstrated a 90.6\%, 61.3\%, and 91.2\% decrease in average latency. Bryan demonstrated a $40.1 \%$ decrease in average latency when put to bed by his father and a $76.5 \%$ in average latency when put to bed by his mother. The shorter latency times across participants were maintained at follow-up for all participants except Bryan. However, Bryan only exhibited long latency times when his mother was responsible for putting him to bed at follow-up (i.e., session 36 and session 37) but not when his dad put him to bed (i.e., session 38). The hypothesis that the implementation of the positive routines procedure would decrease the elapsed time between the parent saying "goodnight" and the child being quiet and in bed (latency) was supported in all four cases. 


\begin{tabular}{|c|c|c|c|c|c|}
\hline Participant & Baseline & Treatment & Follow-up & $\begin{array}{c}\text { Baseline to } \\
\text { Treatment }\end{array}$ & $\begin{array}{c}\text { Baseline to } \\
\text { Follow-up }\end{array}$ \\
\hline Lucy & 30.5 & 2.9 & 5.8 & $\begin{array}{c}90.6 \% \\
\text { decrease }\end{array}$ & $\begin{array}{c}81.0 \% \\
\text { decrease }\end{array}$ \\
\hline Gabriel & 49.3 & 19.5 & 22.8 & $\begin{array}{c}61.3 \% \\
\text { decrease }\end{array}$ & $\begin{array}{c}54.7 \% \\
\text { decrease }\end{array}$ \\
\hline $\begin{array}{c}\text { Bryan } \\
\text { (with dad) }\end{array}$ & 7.9 & 4.8 & 4.7 & $\begin{array}{c}40.1 \% \\
\text { decrease }\end{array}$ & $\begin{array}{c}40.4 \% \\
\text { decrease }\end{array}$ \\
\hline $\begin{array}{c}\text { Bryan } \\
\text { (with mom) }\end{array}$ & 17.8 & 4.2 & 44.6 & $\begin{array}{c}76.5 \% \\
\text { decrease }\end{array}$ & $\begin{array}{c}150.4 \% \\
\text { increase }\end{array}$ \\
\hline Enzo & 8.7 & 0.8 & 0.2 & $\begin{array}{c}91.2 \% \\
\text { decrease }\end{array}$ & $\begin{array}{c}97.6 \% \\
\text { decrease }\end{array}$ \\
\hline
\end{tabular}

Table 3. Average latency (in minutes) and percent changes across phases for each child.

\section{Parental Reinforcing Behaviors}

The percentage of reinforcing behaviors exhibited by the parent participants during the baseline, treatment and follow-up phases of the experiment are presented in Figure 3. The percentage was calculated by dividing the number of times the parent reinforced an instance of noncompliance by opportunities to reinforce and multiplying by 100. For example, if a child exhibited 10 instances of noncompliance during one session and the parent reinforced 7 of these 10 instances, the parent would receive a score of $70 \%$ for that session.

In general there is a slight decrease in the percentage of reinforcing behaviors exhibited by parents from baseline to treatment. On average, Lucy's parent reinforced 78.7\% less of the noncompliance exhibited by Lucy in treatment when compared to baseline. Gabriel's parent demonstrated a 39.4\% decrease in reinforcing behaviors, while Bryan's dad demonstrated a 36.9\% decrease, Bryan's mom demonstrated a 19.7\% decrease, and Enzo's parent demonstrated a 28.4\% decrease. Enzo's parent showed more variability in her data because, when compared to the other children, Enzo exhibited lower levels of noncompliance; when the number is smaller, it is more sensitive to 


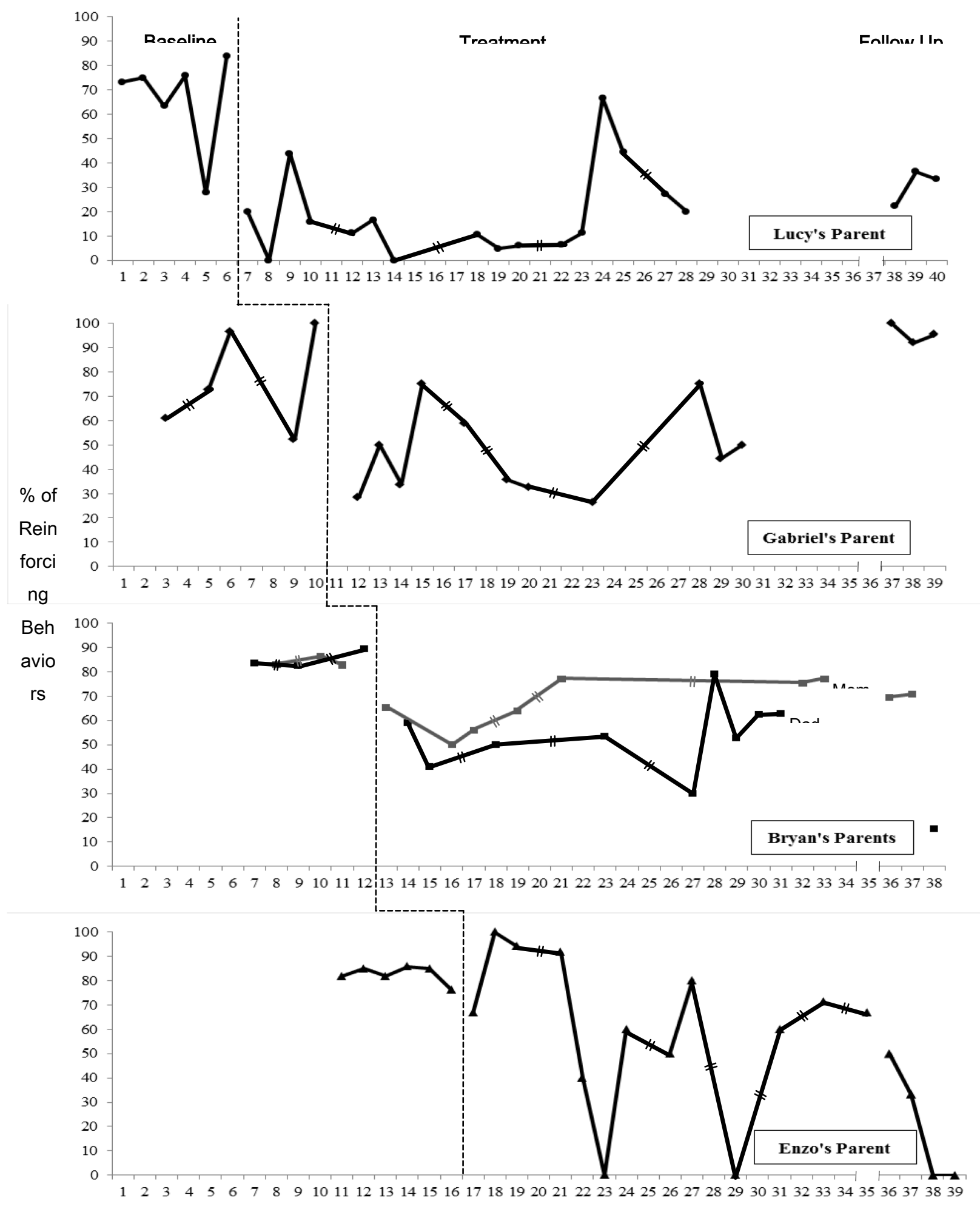

Figure 3. Percentage of reinforcing behaviors exhibited by parents during the three phases of the experiment: (a) baseline, (b) treatment, and (c) follow-up. 
percentages. Nevertheless, by the follow-up phase, Enzo's parent showed the second biggest improvement when compared to the other parents in the study, a $74.8 \%$ decrease in average reinforcing behaviors.

Lucy's parent, Gabriel's parent, Bryan's father, and Bryan's mother demonstrated a $58.7 \%, 25.2 \%, 82.2 \%$, and $15.4 \%$ decrease in average reinforcing behaviors at followup when compared to baseline. Therefore, the findings support the hypothesis that as the frequency of noncompliant behaviors exhibited by the child decreases, the level of parental reinforcing behaviors, those maintaining and/or reinforcing child noncompliance, will also decrease.

\begin{tabular}{|c|c|c|c|c|c|}
\hline Participant & Baseline & Treatment & Follow-up & $\begin{array}{c}\text { Baseline to } \\
\text { Treatment }\end{array}$ & $\begin{array}{c}\text { Baseline to } \\
\text { Follow-up }\end{array}$ \\
\hline $\begin{array}{c}\text { Lucy's } \\
\text { parent }\end{array}$ & $74.2 \%$ & $15.9 \%$ & $30.6 \%$ & $\begin{array}{c}78.7 \% \\
\text { decrease }\end{array}$ & $\begin{array}{c}58.7 \% \\
\text { decrease }\end{array}$ \\
\hline $\begin{array}{c}\text { Gabriel } \\
\text { parent }\end{array}$ & $76.6 \%$ & $46.4 \%$ & $95.8 \%$ & $\begin{array}{c}39.4 \% \\
\text { decrease }\end{array}$ & $\begin{array}{c}25.2 \% \\
\text { increase }\end{array}$ \\
\hline Bryan's dad & $86.3 \%$ & $54.8 \%$ & $15.4 \%$ & $\begin{array}{c}36.9 \% \\
\text { decrease }\end{array}$ & $\begin{array}{c}82.2 \% \\
\text { decrease }\end{array}$ \\
\hline Bryan's mom & $82.7 \%$ & $66.4 \%$ & $70.0 \%$ & $\begin{array}{c}19.7 \% \\
\text { decrease }\end{array}$ & $\begin{array}{c}15.4 \% \\
\text { decrease }\end{array}$ \\
\hline $\begin{array}{c}\text { Enzo's } \\
\text { parent }\end{array}$ & $83.9 \%$ & $60.0 \%$ & $20.8 \%$ & $\begin{array}{c}28.4 \% \\
\text { decrease }\end{array}$ & $\begin{array}{c}74.8 \% \\
\text { decrease }\end{array}$ \\
\hline
\end{tabular}

Table 4. Average percentage of reinforcing behaviors and percent changes across phases for each parent.

To further evaluate the relationship between the change in the child's behavior and the change in their parent's behavior, correlational analyses were conducted using using Spearman's rank correlation. Spearman's rank correlation is a non-parametric statistical test that provides a measure of correlation between ranks (McClave \& Sincich, 2006). A positive correlation between the pairs of ranks is characterized by a positive $r_{s}$. Likewise, a negative correlation between the pairs of ranks is characterized by a negative 
$r_{s}$. Although nonparametric tests generally suffer from the problem of having low power, they are not bound by the same assumptions and rules of parametric statistical tests and are useful when dealing with small samples. The correlation between the average change in the level of child noncompliance from baseline to treatment and the average change in engagement in reinforcing behaviors from baseline to follow-up was calculated. This correlation was not significant $\left(\mathrm{r}_{\mathrm{s}}[5]<.90, \alpha=.05\right)$. The experiment looked at the change from baseline to follow-up because the parent's behavior is presumably under the control of the experimenter during the treatment phase. Nevertheless, the correlation between the average change in the level of child noncompliance from baseline to treatment and the average change in level of parental reinforcing behaviors from baseline to treatment were also calculated. This correlation was significant $\left(\mathrm{r}_{\mathrm{s}}[5]>.90, \alpha=.05\right)$.

\section{Outliers}

Many factors can contribute to outliers in behavioral data aside from human error. Because outliers can result from naturally occurring behavioral phenomena (e.g., spontaneous recovery after extinction), they were not excluded from the behavioral graphs. However, because they significantly affect and skew averages, they were excluded when calculating average levels of noncompliant behaviors, average latency, and average level of parental reinforcing behaviors. Outliers were detected in frequency of noncompliant behaviors exhibited by Lucy (treatment day 3), Gabriel (follow-up day 1), Bryan (treatment day 15) and Enzo (baseline day 1, baseline day 3, and treatment day 3). Lucy and Enzo's outliers during treatment are likely a result of a spontaneous recovery since the positive routines treatment has an extinction component to it. Gabriel's outlier is likely a result of that the recording for that night cut off before the 
child was in bed and quiet for at least 30 minutes. Therefore, there is the high possibility that the child exhibited more bedtime noncompliance than recorded. Bryan's outlier is likely a result of his mother's fidelity score of 0 on that given day.

Outliers were also detected in the percentage of parental reinforcing behaviors. Two outliers were detected in the percentage of reinforcing behaviors exhibited by Lucy's parent (baseline day 5 and treatment day 13) and Enzo's parent (baseline day 5). No other outliers were detected in the other parents' data. Lastly, outliers were detected in latency data for Lucy (treatment day 3) and Bryan (treatment days 9, 11, 14, 15).

\section{Treatment Fidelity}

In calculating correlations between treatment fidelity scores and (1) frequency of noncompliance exhibited by the child, (b) latency, and (c) parental engagement of reinforcing behaviors during treatment and at follow-up, Spearman's rank correlation was utilized. Tests assessing the correlation between treatment fidelity scores and magnitude of change in average noncompliance from baseline to treatment and baseline to follow-up was found to be significant $\left(\mathrm{r}_{\mathrm{s}}[5]>.90, \alpha=.05\right)$. Tests assessing the correlation between treatment fidelity scores and magnitude of change in average percentage of parental reinforcing behavior from baseline to treatment and baseline to follow-up were found not to be significant $\left(\mathrm{r}_{\mathrm{s}}[5]<.90, \alpha=.05\right)$. Likewise, tests assessing the correlation between treatment fidelity scores and magnitude of change in latency from baseline to treatment and baseline to follow-up were found not to be significant $\left(\mathrm{r}_{\mathrm{s}}[5]<.90, \alpha=.05\right)$. Therefore, the findings support the hypothesis that the higher the parent's average treatment fidelity score, the bigger the improvement he/she will observe in their child's behavior. Interestingly, however, the findings did not support the hypotheses that the 
higher the parent's average treatment fidelity: (a) the bigger the change in the percentage of noncompliant behaviors they reinforced during treatment when compared to baseline, and (b) the bigger the change in the percentage of noncompliant behaviors they reinforced during follow-up when compared to baseline.

\section{Discussion}

The findings of the present study validate previous studies' findings on the effectiveness of the positive routines treatment. The hypothesis that the implementation of the treatment would result in decreasing the frequency of bedtime noncompliant behavior exhibited by the children, as well as latency, seems to have been strongly supported by parents who, on average, had medium to high treatment fidelity. Even in the one case where treatment fidelity was extremely low (i.e., Gabriel), a decrease in latency was still evident. Moreover, the study supports previous findings that the decrease in bedtime noncompliant behaviors is maintainable months after treatment has ended; however, only if treatment fidelity was initially high on average. From a theoretical perspective, both classical and operant conditioning may have facilitated treatment efficacy. "From a classical conditioning framework, the unconditioned stimulus is the physiological state associated with sleep deprivation produced by setting the initial bedtime later than the average time of sleep onset during baseline" (Piazza \& Fisher, 1991, p. 137). From an operant perspective, the procedure does have an extinction component to it. During baseline, the parent was more likely to reinforce instances of noncompliant behaviors exhibited by the child. However, during treatment, if noncompliance occurred, parents were instructed to "ignore" or "not give in." 
The present study is unique in that it contributes to the literature of bedtime tantrums in demonstrating objectively how the behavior of the parent changes as a function of change in the child's behavior at bedtime. Moreover, it looks more closely at treatment fidelity and how it influences changes in behavior and latency from baseline to treatment and from baseline to follow-up. Results showed that level of treatment fidelity was correlated with the average decrease in frequency of noncompliant behaviors exhibited by child participants both at treatment and follow-up. It was not correlated with parental reinforcing behaviors or latency. One reason may be that it is still possible to receive a somewhat high treatment fidelity score and simultaneously and inadvertently reinforce problem behavior. Another possible explanation may be that certain guidelines of the treatment protocol may be more important than others in reducing bedtime noncompliance (e.g., observing signs of sleepiness versus reinforcing completion of activities in routine). Notably, it may also be that parents find it extremely difficult to not "give in" to their children's demands, especially when it results in immediate gratification, whereas instructions and feedback from the experimenter are not received until the following day. Behavioral research has continuously shown that the more immediate the consequence, the more effective it is in modifying behavior. However, because the positive routines treatment takes into account the biological aspect of sleep, children may be less inclined to exhibit noncompliant behaviors because they are already sleepy. Therefore, if the parent does not consistently follow the treatment guidelines perfectly, the routine may still be effective in reducing the level of noncompliant behaviors exhibited by the child even if it may not necessarily have as much of a dramatic effect on decreasing parental reinforcing behaviors. Nevertheless, the positive 
routines treatment was still effective in reducing the percentage of noncompliant behaviors the parent reinforced.

Additionally, it was found that the bigger the improvement in the child's behavior in treatment, compared to baseline, the bigger the improvement in the parent's behavior at the same time (baseline to treatment). Unfortunately, this relationship did not hold true when the experimenter tested the correlation between the change in level of noncompliance from baseline to treatment and the change in level of reinforcing behaviors from baseline to follow-up. One possible reason for this discrepancy is that there were significantly few data points for follow-up than for treatment. For instance, Bryan's father only had one data point at follow-up. Moreover, Bryan's data show an increase in average latency from treatment to follow-up and a very slight increase in average parental reinforcing behaviors from treatment to baseline. His mother noted that she decided to go back to school after treatment ended and "gives in" more to her child's demands at bedtime because she feels "guilty" about having less time to spend with him.

\section{Future Directions}

Future studies should look specifically at the positive routines treatment guidelines. A component analysis could be done to determine which of the guidelines are more fundamental in the efficacy of the positive routines treatment.

\section{Limitations}

One possible limitation of this study is the extent to which extraneous variables influenced the data. Because the study took place in home settings, the behavior of the child and the parent could have been influenced by a number of factors that were not accounted for (e.g., visiting guests). Another limitation is the fact that Bryan had two 
parents implementing the routine, whereas the other children only had one parent. Bryan having two parents involved in the study meant that one participant in this delayed multiple baseline study had a fundamentally different condition than the rest of the participants in the study. Involving both parents was not the intent of the experimenter. Initially, it was the father who was going to implement the routine; however, shortly after the study began, his job required him to travel more often leaving the mother responsible for carrying out the bedtime routine on certain days. A third limitation was the use of only audio-recorders. Although much of the interactions between the parents and the child were audible (e.g., conversations and kisses) and some inaudible interactions (e.g., hugs) were alluded to verbally, it was impossible for the experimenter to count every instance of interaction between the parent and the child. Smiles, frowns, touch, or simple eye contact which are known to be reinforcing, may have been missed. Video recorders could have helped solve this limitation; however, parents might have found this solution to be extremely intrusive. A fourth limitation of the present study is that the data are discontinuous. Because most parents do not enforce bedtimes on the weekends (Friday night and Saturday night), data were not collected these days. Moreover, even on days when data should have been collected, sometimes parents did not turn on the recorders. This was particularly true for Gabriel's parent. Reasons included: (a) not having charged the audio-recorder in time, (b) coming home late and the child falling asleep in the car, and (c) going on an impromptu vacation. A fifth limitation of the study was the use of such a small sample size. Recruitment was extremely difficult for this study; therefore, a small sample size of four children was used. Although small sample sizes are extremely common and well-accepted in behavior analytic research, the use of such a small sample 
size meant the required use of nonparametric statistics, which are less powerful and more susceptible to Type I error than parametric statistics. Moreover, because the four families were recruited from the same area (i.e., South Florida), they were all ethnically homogenous; they were all Hispanic. A sixth and final limitation is in regard to the latency measure. Each child had a different routine and the amount of time the routine took depended on more than just treatment fidelity. For example, if one activity was a drink before bed but the child was not thirsty on a given night, this would not mean that the child was more or less compliant or that the parent was less effective in implementing the treatment. Moreover, if the bedtime story read to them one night was longer than the bedtime story read to them on another night, this would unreasonably affect latency for that night. Because each child either had a bedtime story or prayer at the end of their routine and each child showed more noncompliance after being put to bed than before, the point at which that activity (i.e., bedtime story or prayer) ended was considered the "starting point" for latency calculations. However, it is very possible, and likely, that noncompliant behaviors extending bedtime were exhibited before that point.

\section{Conclusion}

Despite the limitations, the current study contributed to the vast literature not only on how parent's can modify their child's behavior, but more importantly, it examined the effect of the child's behavior on the behavior of the parent using a significantly more objective approach than have been traditionally used. Anecdotally, parents of the children all reported a high degree of satisfaction with their child's improvement in behavior. This is important for two reasons. First, parents reported that they learned how to manage their child's noncompliance at bedtime more effectively. More importantly is 
that for Gabriel, there was really no decrease in noncompliance. This emphasizes the importance of observing and collecting objective data, particularly since data on the behavior of parents and caretakers are particularly rare in the sleep literature. With the use of objective data, it is easier to acknowledge the reciprocity in behavioral problems and the procedures used to eliminate them. Recognition of these back-and-forth relationships provide a basis for understanding early social development and parent-child interactions. 


\section{References}

Adams, L. A. \& Rickert, V. I. (1989). Reducing bedtime tantrums: Comparison between positive routines and graduated extinction. Pediatrics, 84, 756-761.

Baer, D. M., Wolf, M. M, \& Risely, T. R. (1968). Some current dimensions of applied behavior analysis. Journal of Applied Behavior Analysis, 1, 91-97.

Blader, J. C, Koplewicz, H. C, Abikoff, H., \& Foley, C. (1997). Sleep problems of elementary school children: A community survey. Archives of Pediatrics and Adolescent Medicine, 151, 473-480.

Chorney, D. B., Detweiler, M. F., Morris, T. L., \& Kuhn, B. R. (2007). The interplay of sleep disturbance, anxiety, and depression in children. Journal of Pediatric Psychology, 33, 339-348.

Cipani, E. (1998). Three behavioral functions of classroom noncompliance: Diagnostic and treatment implications. Focus on Autism and Other Developmental Disabilities, 13, 66-72.

Cooper, J. O., Heron, T. E., \& Heward, W. L. (2007). Applied Behavior Analysis. Upper Saddle River, NJ: Prentice Hall.

Dahl, R. E. (1996). The impact of inadequate sleep on children's daytime cognitive function. Seminars in Pediatric Neurology, 3, 44-50.

Dougherty, E. H., \& Lane, J. R. (1976). Naturalistic alternatives to extinction: An application to self-injurious bedtime behavior. Journal of Behavior Therapy and Experimental Psychiatry, 7(4), 373-375.

Edwards, K. J., \& Christophersen, E. R. (1994). Treating common sleep problems of young children. Developmental and Behavioral Pediatrics, 15, 207-213.

Family Structure \& Poverty. (2008). American Community Survey, 2000 U.S. Census Bureau. Retrieved from http://www.miamidade.gov/planzone/Library/narratives/ Household Structure ChangesGlance.pdf.

Ferber, R. (1985). Sleep, sleeplessness, and sleep disruptions in infants and young children. Annals of Clinical Research, 17(5), 227-234.

Friman, P. C., Hoff, K. E., Schnoes, C., Freeman, K. A., Woods, D. W., \& Blum, N. (1999). The bedtime pass: An approach to bedtime crying and leaving the room. Archives of Pediatric and Adolescent Medicine, 153, 1027-1029. 
Galbraith, L. R., Pritchard, L., \& Hewitt, K. E. (1993). Behavioural treatment for sleep disturbances. Health Visitor, 66, 169-171.

Gewirtz, J. L. (1969). Mechanisms of social learning: Some roles of stimulation and behavior in early human development. In D. A. Goslin (Ed.), Handbook of socialization theory and research (pp. 57-212). Chicago: Rand McNally.

Gewirtz, J. L. (1976). The attachment acquisition process as evidenced in the maternal condition of cued infant responding (particularly crying). Human Development, 19, 143-155.

Gewirtz, J. L. (1991). Social influence on child and parent via stimulation and operantlearning mechanisms. In M. Lewis \& S. Friedman (Eds.), Social influences and socialization in infancy (pp. 137-163). New York: Plenum Press.

Gewirtz, J. L. \& Boyd, E. F. (1977). Experiments on mother-infant interaction underlying mutual attachment acquisition: The infant conditions the mother. In T. Alloway, P. Plines, \& L. K. Krames (Eds.), Advances in the study of communication and affect: Vol. 3. Attachment behavior (pp. 109-143). New York: Plenum Press.

Gewirtz, J. L. \& Pelaez-Nogueras, M. (1990, April). Complications of mother/stranger responding in maternal departures and in the strange situation: A functional analysis. In New Research Directions in Attachment \& Strange-Situation Behavior. Symposium conducted at the International Conference of Infant Studies, Montreal, Canada.

Gewirtz, J. L. \& Pelaez-Nogueras, M. (1993). Leaving without tears: Parents inadvertently train their children to protest separation. Child and Adolescent Behavior Letter, 9, 1-4.

Goodnight, J. A., Bates, J. E., Staples, A. D., Pettit, G. S., \& Dodge, K. A. (2007). Temperamental resistance to control increases the association between sleep problems and externalizing behavior development. Journal of Family Psychology, 21, 39-48.

Gregory, A. M., Eley, T. C., O’Connor, T. G., \& Plomin, R. (2004). Etiologies of associations between childhood sleep and behavioral problems in a large twin sample. Journal of the American Academy of Child and Adolescent Psychiatry, 43, 744-751.

Gregory, A. M., \& O'Connor, T. G. (2002). Sleep problems in childhood: A longitudinal study of developmental change and association with behavioral problems. Journal of the American Academy of Child and Adolescent Psychiatry, 41, 964-971. 
Jencius, M. J. \& Rotter, J. C. (1998). Bedtime rituals and their relationship to childhood sleep disturbances. The Family Journal, 6, 94-105.

Kuhn, B. R., Mayfield, J. W., \& Kuhn, R. H. (1999). Clinical assessment of child and adolescent sleep disturbance. Journal of Counseling and Development, 1999, 77, 359-368.

Lavigne, J. V., Arend, R., Rosenbaum, D., Smith, A., Weissbluth, M., Binns, H. J., et al. (1999). Sleep and behavior problems among preschoolers. Journal of Developmental and Behavioral Pediatrics, 20, 164-169.

Liu, J. (2004). Childhood externalizing behavior: Theory and implications. Journal of Child and Adolescent Psychiatric Nursing, 17(3), 93-103.

Mattson, I. E. A component analysis of the positive routines treatment package in the treatment of bedtime tantrums and other sleep problems of preschool children. Dissertation Abstracts International: Section B: The Sciences and Engineering, 1426. http://search.proquest.com/docview/619005784?accountid= 10901.

Milan, M. A., Mitchell, P. Z., Berger, M. I., \& Pierson, D. F. (1981). Positive routines: A rapid alternative to extinction for elimination of bedtime tantrum behavior. Child Behavior Therapy, 3(1), 13-25.

Mindell, J. A. (1993). Sleep disorders in children. Health Psychology, 12, 151-162.

Moore, B. A., Friman, P. C., Fruzzetti, A. E., \& MacAleese, K. (2007). Brief report: Evaluating the bedtime pass program for child resistance to bedtime $-\mathrm{A}$ randomized, controlled trial. Journal of Pediatric Psychology, 32(3), 283-287.

Moore, M. (2010). Bedtime problems and night waking: Treatment of behavioral insomnia of childhood. Journal of Clinical Psychology: In Session, 66(11), $1195-$ 1204.

Ortiz, C., \& McCormick, L. (2007, June 22). Behavioral parent-training approaches for the treatment of bedtime noncompliance in young children. The Free Library. (2007). Retrieved February 04, 2010 from http://www.thefreelibrary.com/ Behavioral parent-training approaches for the treatment of bedtime...a0170115173.

Piazza, C. C., \& Fisher, W. (1991). A faded bedtime with response cost protocol for treatment of multiple sleep problems in children. Journal of Applied Behavior Analysis, 24, 129-140. 
Ravid, S., Afek, I., Suraiya, S., Shahar, E., \& Pillar, G. (2009). Kindergarten children's failure to qualify for first-grade could result from sleep disturbances. Journal of Child Neurology, 24, 816-822.

Sadeh, A., Raviv, A., \& Gruber, R. (2000). Sleep patterns and sleep disruptions in school-age children. Developmental Psychology, 36(3), 291-301.

Salzarulo, P., \& Chevalier, A. (1983). Sleep problems in children and their relationships with early disturbances of the waking-sleeping rhythms. Sleep, 6, 47-51.

Taylor, D. J., \& Roane, B. M. (2010). Treatment of insomnia in adults and children: A practice-friendly review of research. Journal of Clinical Psychology: In Session, 66(11), 1137-1147.

Wade, C. M., Ortiz, C. \& Gorman, B. S. (2007). Two-session group parent training for bedtime noncompliance in head start preschoolers. Child \& Family Behavior Therapy, 29, 23-55.

Wilder, D. A., Harris, C., Reagan, R. and Rasey, A. (2007). Functional analysis and treatment of noncompliance by preschool children. Journal of Applied Behavior Analysis, 40, 173-177. 
Appendices

A. Informed Consent Form

B. Measures

C. Recruitment Flyer 
Appendix A: Informed Consent 


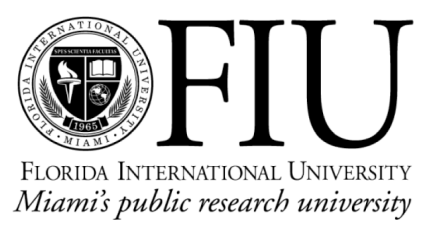

CONSENT TO PARTICIPATE IN A RESEARCH STUDY

\section{Title: Interactions at Bedtime: A Bidirectional View of Noncompliant Bedtime Behavior}

We would like you and your child to be in a research study. The investigator of this study is Desiree Espinal and she is a graduate student at FIU. The study will include about four preschool children exhibiting bedtime refusal behaviors and their parents. The study will require about two hours each weeknight around bedtime for two to three nonconsecutive months. Baseline will take place over a one to two week period, while the treatment phase is expected to last six to eight weeks during the last two months of the school year. Follow-up is expected to take place once the next school year has started (approximately two and a half months later) and is to last one week. The study intends to (a) decrease the time it takes the child to go to bed after being instructed to do so (latency), (b) decrease the children's frequency of bedtime noncompliant behaviors, and (c) shed light on the interactions at bedtime.

During the pre-experiment phase, you will be interviewed by the experimenter. You will be asked to report on the number of nights the child engages in bedtime noncompliance during a typical week, what types of noncompliance behaviors the child exhibits, questions regarding how you respond to these behaviors, and desired bedtime. Furthermore, investigators will inquire about your child's medical history (including medications), clinical diagnoses, as well as family structure. If your family meets the inclusion criteria, you will be explained how positive routines work and how it should be implemented. Furthermore, you will be explained how and for how long data is to be collected and if you are willing to comply. If you are, you will be given a 10-question quiz in order to ensure that they completely understand the intervention and general behavior modification concepts.

During the baseline phase, if selected to continue on, we will ask you to continue doing whatever you normally do when their child does not comply at bedtime to give investigators an idea of the factors involved in your child's bedtime refusal. Treatment will be provided if no improvement is seen in your child's behavior.

During the treatment phase, you and the researcher will select ideal bedtimes for each child, based on when he or she naturally fell asleep. You will be told to construct a "positive routine" from four to seven activities lasting no longer than a total of 20 minutes and instructed to praise their child after each activity in the routine. At the completion of all four to seven activities, you are to instruct your child to go to sleep. If 
at any time after the completion of the routine your child begins to engage in noncompliant behaviors, you are to place the child back in bed, saying firmly, "The routine is over; it is time for bed!" After week one, the positive routine will begin five to ten minutes earlier each week so that by the beginning of week five, the routine is completed at the time you and the investigator had originally attempted to establish as bedtime. At the end of the treatment phase, the investigator will remind you that treatment has officially ended but she will follow up in about two to three months.

During follow-up, the investigator will check to see the progress of the child. At this time, you will resume data collection as before for one week.

There are no known risks related to the surveys. You may skip any questions that you do not want to answer. If you feel discomfort at any time you may ask to take a break. There is no cost or payment to you or your child as a subject. Your help will give us information about the factors contributing to bedtime noncompliance. In addition you may learn about new ways to help your child.

A random number, not your names, will identify your data. All of your answers are private and will not be shared with anyone unless required by law. The results will be presented as a group at conferences and in a paper.

You may ask questions about the study at any time. If you choose not to continue in the study no one will be upset with you.

If you would like to know more about this research after you are done, you can contact me, Dr. Most, at 305-305-3053. If you feel that you or your child were mistreated or you have questions about your rights as a volunteer in this research study you may contact Dr. Patricia Price, the Chairperson of the FIU Institutional Review Board at 305-348-2618 or 305-348-2494.

If you have had all of your questions answered to your liking and you would like to be in the study, sign below. Your signature also indicates that you will allow your child to be in the study.

(Print child's name)

Signature of Participant

Date

I have explained the research procedure, subject rights and answered questions asked by the participant. I have offered him/her a copy of this informed consent form.

Signature of Witness

Date 


\section{Appendix B: Measures}

\section{Sleep Interview}

2. Positive Routines Comprehension Quiz 


\section{Sleep Interview}

Child's Name:

Child's Age: years months

Today's Date:

\section{Child's Developmental, Medical and Psychiatric History}

1. Has your child ever been diagnosed with any developmental delay? Yes No . If yes, please specify:

2. Has your child ever been diagnosed with any medical, psychological, and/or behavioral disorders? Yes No . If yes, please specify:

3. Is your child currently taking any prescription/psychoactive medications (including medications used for sleep)? Yes No . If yes, please specify:

\section{History of Current Sleep Problems}

1. Does your child ever protest bedtime? Yes occur? daily or times a week or

No . If yes, how often does it times a month.

2. About how long do these protests last?

3. Aside from protests (e.g., crying, calling out, arguing), what (if any) other noncompliant behaviors does your child engage in once instructed to go to bed?

4. Have you made past attempts to treat your child's noncompliance at bedtime? Yes No . If yes, how have you attempted to solve the problem?

5. Do you anticipate any bedtime noncompliance tonight? If so, what kind of noncompliance would be typical? 


\section{Bedtime}

1. Does your child have an establish bedtime? Yes __ No __ If yes, what time?

2. Around what time does your child naturally fall asleep?

3. Does your child complain that he or she is not tired at his or her usual bedtime? Yes __ No __. If yes, how often? __ daily or __ times a week or __ times a month.

\section{Habits and Routines}

1. Who is responsible for getting the child to bed? waking the child in the morning?

2. What activity, or activities, is the child usually engaged in right before bedtime? (e.g., watching television)

\section{Sleep Environment}

1. Where does the child typically fall asleep? (e.g., parents' bed, couch, his/her own bed)?

2. Where and with whom does the child sleep?

\section{Parental Soothing Strategies}

1. If your child protests at bedtime, how are protests handled?

2. Does your child ever ask you to join in your bed? Yes No __. If yes, how often does this occur? responded? times a week or times a month. How have you 
3. Does your child ever request a room search (e.g., under the bed, in the closets) prior to or shortly after going to bed? Yes __ No __. If yes, how often does your child request this? times a month or times a week.

Comments:

4. How you ever sat with your child to calm him or her to get to sleep? Yes No

. If yes, how often has this occurred? times a month or times a week. Comments:

5. What other soothing behaviors do you engage in to help your child go to sleep? (e.g., nursing/feeding child, holding/rocking the child to sleep, medicating the child)

\section{Child's Behavioral Signs of Sleepiness}

Check all that apply:

Rubs eyes

More active

Whining

Crying

Clings to parent

Other (please specify):

\section{Any further comments about your child's sleep...}




\section{Positive Routines Comprehension Quiz}

1. What happens to a behavior when it is reinforced?

2. When should reinforcement occur (relative activity completion)?

a. At the end of the chain.

b. In the morning after the child has woken up.

c. Immediately after compliance with each activity in the chain.

3. True or False: Reprimands can function as a reinforcer.

4. Which of the following is/are NOT (a) guideline(s) that must be followed when implementing Positive Routines?

a. Ending all stimulating and enjoyable activities in which your child is engaged (e.g., television).

b. Observing your child for signs of sleepiness.

c. Rapidly fading the starting time of the chain back from the natural time the child goes to sleep to the time you prefer.

5. An example of appropriately fading the starting time of the chain is...

a. starting the chain earlier every night regardless of whether the child appears sleepy or not

b. gradually starting the chain earlier as sleepiness becomes apparent

c. starting the chain so that it ends at the time you want the child to go to sleep from the beginning

6. If your child exhibits noncompliance during the routine, what should be done?

7. True or False: Praise should follow compliance with every activity within the chain.

8. The child getting in bed should be reinforced...

a. with praise only

b. with praise and a bedtime story

c. initially, with the parent sleeping in bed

9. Which types of activities should be included in the Positive Routines?

a. Self help activities that prepare the child for bed. 
b. Stimulating activities (e.g., watching TV, playing video games or board games with parent).

c. Activities that have been resisted by the child in the past.

10. True or False: It is not necessary to reinforce the child's sleeping behavior by providing praise when the child wakes up the next morning. 
Appendix D: Recruitment Flyer 


\section{Bedtime BLUeS?}
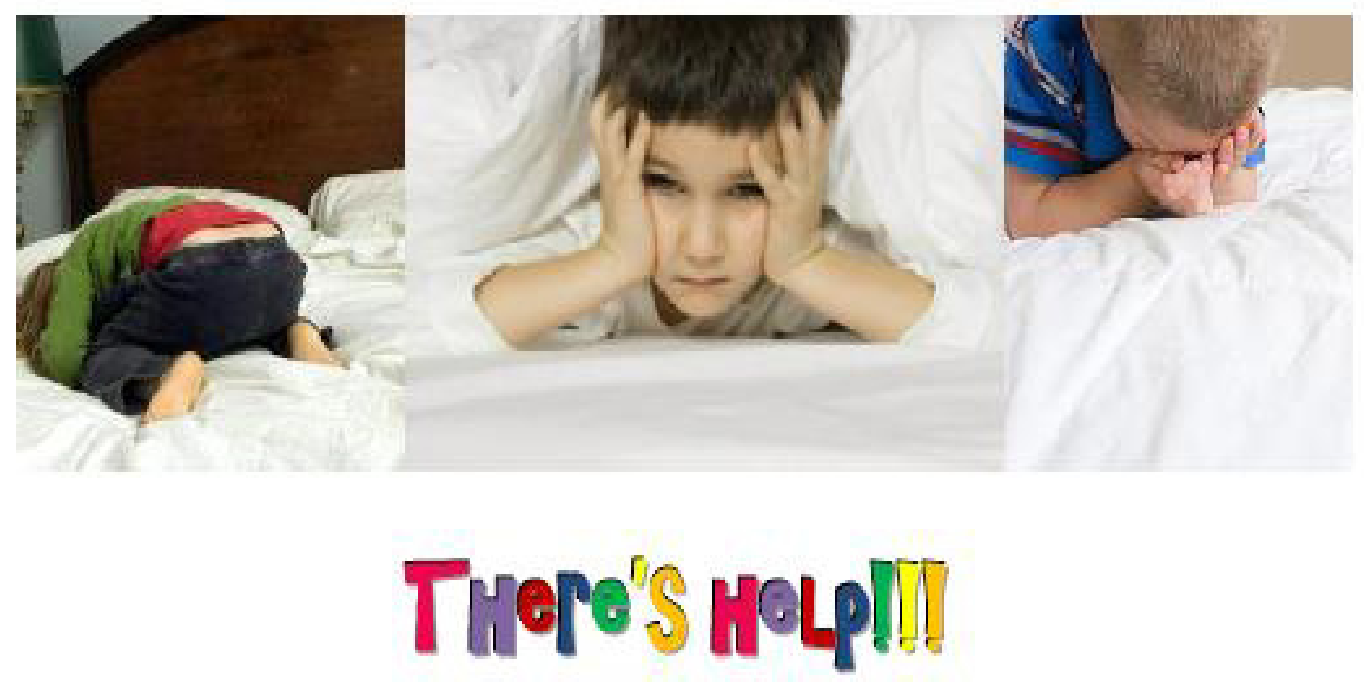

1. Do you bave a child who exhibits nopcompliance at bedtime?

- Stalling or making excuses - Leaving the bedroom Physical aggression (e.g., throwing objects, bitting) - Protesting (e.g., arguing, crying, calling out) - Ignoring instructions to go to bed

2. Do you live in Miami Dade County, fl?

3. Are you are willing to participate in a research study?

If you've answered yes to all, please contact Desiree Espinal at (305) 791-6998 or despi007@fiu.edu

The aims of the study are: (a) to reduce noncompliance at bedtime, (b) to reduce the time it takes the child to go to bed after being instructed to do so, and (c) to study the interactions taking place.

The child must:

- Be 4 to 7 years old

- Exhibit bedtime refusal behaviors at least 4 days in a typical week

- Not be diagnosed with any psychological or medical disorders

- Not be diagnosed with any developmental delays 